\title{
Inflammatory Mediators Alter the Astrocyte Transcriptome and Calcium Signaling Elicited by Multiple G-Protein-Coupled Receptors
}

\author{
Mary E. Hamby, ${ }^{1}$ Giovanni Coppola, ${ }^{2,4}$ Yan Ao, ${ }^{1}$ Daniel H. Geschwind, ${ }^{2,4}$ Baljit S. Khakh, ${ }^{1,3}$ and Michael V. Sofroniew ${ }^{1}$ \\ ${ }^{1}$ Departments of Neurobiology, ${ }^{2}$ Neurology, ${ }^{3}$ Physiology, and ${ }^{4}$ Semel Institute for Neuroscience and Human Behavior, David Geffen School of Medicine, \\ University of California Los Angeles, Los Angeles, California 90095-1763
}

Inflammation features in CNS disorders such as stroke, trauma, neurodegeneration, infection, and autoimmunity in which astrocytes play critical roles. To elucidate how inflammatory mediators alter astrocyte functions, we examined effects of transforming growth factor- $\beta 1$ (TGF- $\beta 1$ ), lipopolysaccharide (LPS), and interferon-gamma (IFN $\gamma$ ), alone and in combination, on purified, mouse primary cortical astrocyte cultures. We used microarrays to conduct whole-genome expression profiling, and measured calcium signaling, which is implicated in mediating dynamic astrocyte functions. Combinatorial exposure to TGF- $\beta 1$, LPS, and IFN $\gamma$ significantly modulated astrocyte expression of $>6800$ gene probes, including $>380$ synergistic changes not predicted by summing individual treatment effects. Bioinformatic analyses revealed significantly and markedly upregulated molecular networks and pathways associated in particular with immune signaling and regulation of cell injury, death, growth, and proliferation. Highly regulated genes included chemokines, growth factors, enzymes, channels, transporters, and intercellular and intracellular signal transducers. Notably, numerous genes for G-protein-coupled receptors (GPCRs) and G-protein effectors involved in calcium signaling were significantly regulated, mostly down (for example, Cxcr4, Adra2a, Ednra, P2y1, Gnao1, Gng7), but some up (for example, P2y14, P2y6, Ccrl2, Gnb4). We tested selected cases and found that changes in GPCR gene expression were accompanied by significant, parallel changes in astrocyte calcium signaling evoked by corresponding GPCR-specific ligands. These findings identify pronounced changes in the astrocyte transcriptome induced by TGF- $\beta 1$, LPS, and IFN $\gamma$, and show that these inflammatory stimuli upregulate astrocyte molecular networks associated with immune- and injury-related functions and significantly alter astrocyte calcium signaling stimulated by multiple GPCRs.

\section{Introduction}

Both inflammation and reactive astrogliosis are features of many CNS disorders including stroke, trauma, neurodegeneration, infection, and autoimmunity (Lucas et al., 2006; Barres, 2008; Sofroniew and Vinters, 2010), yet how their interactions influence one another is not well understood. Astrocytes produce and respond to numerous molecules involved in immune and inflammatory signaling, including chemokines, cytokines, growth factors, and many small molecules (Eddleston and Mucke, 1993; John et al., 2003; Lovatt et al., 2007; Cahoy et al.,

Received March 13, 2012; revised Aug. 15, 2012; accepted Aug. 17, 2012.

Author contributions: M.E.H., B.S.K., and M.V.S. designed research; M.E.H., G.C., and Y.A. performed research; M.E.H., G.C., D.H.G., B.S.K., and M.V.S. analyzed data; M.E.H., G.C., D.H.G., B.S.K., and M.V.S. wrote the paper.

This work was supported by grants from National Institutes of Health NS057624 (M.V.S.), NS060677, NS071292, and NS063186 (B.S.K.); T32-MH19925 through the Cousins Center for Psychoneuroimmunology at University of California Los Angeles (UCLA) (M.E.H.); The Dr. Miriam and Sheldon G. Adelson Medical Foundation (M.V.S., G.C., and D.H.G.); and National Institute of Neurological Disorders and Stroke P30NS062691 through the UCLA Informatics Center for Neurogenetics and Neurogenomics. Thanks to Dr. Eiji Shigetomi for guidance on calcium imaging and to Fuying Gao for help with data analysis.

The authors declare no competing financial interests.

Correspondence should be addressed to Michael V. Sofroniew, Department of Neurobiology, David Geffen School of Medicine, University of California Los Angeles, 10833 Le Conte Avenue, Los Angeles, CA 90095-1763. E-mail: sofroniew@mednet.ucla.edu.

DOI:10.1523/JNEUROSCI.1256-12.2012

Copyright $\odot 2012$ the authors $\quad 0270-6474 / 12 / 3214489-22 \$ 15.00 / 0$
2008; Sofroniew, 2009; Zamanian et al., 2012). Nevertheless, the roles that astrocytes play during CNS immune and inflammatory responses, and the effects of inflammatory mediators on astrocyte functions, are not well defined.

During CNS inflammation, multiple cell types can produce multiple inflammatory mediators. Combinatorial interactions of inflammatory signaling molecules are becoming recognized as able to provide unique instructions to specific cells, as demonstrated for certain immune cells (Korn et al., 2009). In contrast, combinatorial effects of multiple inflammatory mediators on astrocytes are unclear. In this study, we (1) determined the combinatorial effects of several representative inflammatory mediators on astrocyte gene expression profiles in vitro, (2) used bioinformatic data analyses to look for changes that might impact on specific astrocyte functions, and (3) examined the functional consequences of certain gene expression changes.

As representative inflammatory mediators we examined transforming growth factor- $\beta 1$ (TGF- $\beta 1$ ), a cytokine produced during CNS inflammation in many disorders (Lindholm et al., 1992; Krupinski et al., 1996; Ata et al., 1997; Swardfager et al., 2010; Friedman and Dingledine, 2011), and lipopolysaccharide (LPS) and interferon-gamma (IFN $\gamma$ ), 
which are canonical innate inflammatory mediators used extensively to study cellular responses to inflammation (Raetz and Whitfield, 2002; Schroder et al., 2004; Daginakatte et al., 2008). Microglial production of factors like IFN $\gamma$ upregulate expression of toll-like receptors in astrocytes (Holm et al., 2012). There are numerous contexts in vivo during CNS disorders in which astrocytes are exposed to combinations of TGF- $\beta 1$ and innate inflammatory mediators such as LPS and IFN $\gamma$. We have shown previously that TGF- $\beta 1$ enhances the LPS and IFN $\gamma$-induced expression of inducible nitric oxide synthase (iNOS) or cyclooxygenase-2 in astrocytes (Hamby et al., 2006a, 2008, 2010).

Here, we asked how these inflammatory mediators, alone and in combination, might alter astrocyte functions by modulating entire gene expression profiles. We conducted genome-wide microarray profiling and bioinformatic analyses (Coppola et al., 2009; Coppola, 2011) on well characterized preparations of purified primary astrocyte cultures (Hamby et al., 2006b) exposed to TGF- $\beta 1$, LPS, and IFN $\gamma$ alone and in combination. Expression levels of many genes, molecular networks, and functional pathways were significantly altered. Our attention was drawn particularly to changes in numerous G-protein-coupled receptors (GPCRs) and their intracellular effectors because of the potential impact on astrocyte functions. Changes in GPCRs are implicated in various inflammatory conditions (Lattin et al., 2007) and GPCRs play central roles in astrocyte calcium signaling. Astrocytes display spontaneous and ligand-evoked intracellular calcium concentration $\left(\left[\mathrm{Ca}^{2+}\right]_{i}\right)$ increases that represent a form of astrocyte excitability, and signaling via changes in astrocyte $\left[\mathrm{Ca}^{2+}\right]_{i}$ is under investigation as a means of mediating dynamic astrocyte functions, including interactions with synapses and regulation of blood flow (Verkhratsky et al., 1998; Iadecola and Nedergaard, 2007; Barres, 2008; Attwell et al., 2010; Halassa and Haydon, 2010). We therefore evaluated astrocyte calcium signaling evoked by ligands of various GPCRs and found that changes in gene expression induced by combinatorial inflammatory treatment were accompanied by parallel changes in ligand-evoked $\left[\mathrm{Ca}^{2+}\right]_{i}$ increases.

\section{Materials and Methods}

Astrocyte culture. Primary astrocyte cultures were prepared from cerebral cortices of postnatal (1-3-d-old), male and female C57BL/6 mice as previously described (Hamby et al., 2006a,b). In brief, plating media consisted of L-glutamine-free DMEM (Invitrogen) supplemented with $10 \%$ fetal bovine serum (Hyclone), 10\% calf serum (CS; Hyclone), $2 \mathrm{~mm}$ L-glutamine, $50 \mathrm{IU} / \mathrm{ml}$ penicillin, $50 \mu \mathrm{g} / \mathrm{ml}$ streptomycin, and $10 \mathrm{ng} / \mathrm{ml}$ epidermal growth factor (R\&D Systems). Upon confluence, astrocyte cultures were purified of microglia by treatment with $8 \mu \mathrm{M}$ cytosine $\beta$-D-arabinofuranoside (Sigma) for $5-6 \mathrm{~d}$ to substantially reduce microglia followed by treatment with $75 \mathrm{~mm}$ L-leucine methyl ester (Sigma, 60-90 $\mathrm{min}$ ) $1 \mathrm{~d}$ before experimentation to completely eradicate any residual microglia (Hamby et al., 2006a,b). Cells were maintained in medium consisting of L-glutamine-free DMEM, $10 \%$ CS, 2 mM L-glutamine, $50 \mathrm{IU} / \mathrm{ml}$ penicillin, and $50 \mu \mathrm{g} / \mathrm{ml}$ streptomycin. For imaging experiments, astrocytes were passaged onto glass coverslips. All cultures were maintained at $37^{\circ} \mathrm{C}$ in a humidified atmosphere of $6 \% \mathrm{CO}_{2}$ and used after $14-31 \mathrm{~d}$ in vitro.

Cytokine and endotoxin exposure. Purified astrocyte cultures were exposed to four different experimental stimulation conditions in stimulation medium (SM), which consisted of L-glutamine-free DMEM supplemented with $5 \%$ CS, $2 \mathrm{~mm}$ L-glutamine, $50 \mathrm{IU} / \mathrm{ml}$ penicillin, and $50 \mu \mathrm{g} / \mathrm{ml}$ streptomycin. (1) Basal (B): 32 or $\sim 48 \mathrm{~h}$ in SM; (2) TGF- $\beta 1$ (T): 32 or $\sim 48 \mathrm{~h}$ in SM with TGF- $\beta 1(3 \mathrm{ng} / \mathrm{ml}$; human recombinant, R\&D Systems); (3) LPS + IFN $\gamma$ (LG ); $24 \mathrm{~h}$ in SM before addition of LPS (Escherichia coli 0127:B8, $2 \mu \mathrm{g} / \mathrm{ml}$; Sigma) plus IFN $\gamma$ (recombinant mouse, $3 \mathrm{ng} / \mathrm{ml}$; R\&D Systems) for a further 8 or $\sim 24 \mathrm{~h}$; (4) TGF- $\beta 1+$ LPS + IFN $\gamma$ (TLG): $24 \mathrm{~h}$ in SM with TGF- $\beta 1$ before addition of LPS + IFN $\gamma$ for a further 8 or $\sim 24 \mathrm{~h}$, for mRNA expression analyses, or $\left[\mathrm{Ca}^{2+}\right]_{i}$ imaging, respectively. The $24 \mathrm{~h}$ duration of TGF- $\beta 1$ treatment before addition of SM alone or that with LPS plus IFN $\gamma$ was chosen on the basis of previous experiments showing a maximal and stable effect of TGF- $\beta 1$ on induction of iNOS and enhancement of nitric oxide production in purified astrocyte cultures over this time period (Hamby et al., 2006a). In agreement with previous studies, no cytopathological changes were observed in the astrocytes following treatment with these agents at the doses used in the present studies.

Microarray profiling and analysis. Microarray profiling was performed as previously described (Coppola et al., 2009; Sarafian et al., 2010; Coppola, 2011). In brief, total RNA was isolated from astrocytes using the Qiagen RNeasy Kit. RNA quantity and quality was assessed using a Nanodrop (Nanodrop Technologies) and the Agilent Bioanalyzer (Agilent Technologies), respectively. Total RNA (200 ng) was amplified, biotinylated, and hybridized on Illumina Mouse ref- 8 v2.0 BeadChip arrays, querying the expression of $\sim 25,600$ well annotated Refseq transcripts, as per manufacturer's protocol. Slides were scanned using Illumina BeadStation and signal extracted using Illumina BeadStudio software (Illumina).

Raw data were analyzed using Bioconductor packages (www. bioconductor.org). Quality-control analysis was performed using several indices including interarray Pearson correlation, clustering based on variance, and the mean absolute deviation (MAD) using the top 1000 most variant probes (Coppola, 2011). Data were normalized using quantile normalization. Analysis of differential expression was performed using linear model fitting (LIMMA package) (Smyth, 2004). After linear model fitting, a Bayesian estimate of differential expression was calculated using a false discovery rate (FDR) of 5\%. Nonsignificant (NS) results indicate no change in expression levels relative to the basal or treated cells as indicated. NS does not indicate whether the cells actually express the gene or not. Raw and normalized data have been deposited in NCBI's Gene Expression Omnibus (Edgar et al., 2002) and are accessible through GEO Series accession number GSE36089 (http://www.ncbi.nlm.nih.gov/ geo/query/acc.cgi?acc $=$ GSE36089). Pathway and network analyses were performed using Ingenuity Pathway Analysis (Ingenuity Systems; www. ingenuity.com). Venn diagram was made using SmartDraw software.

Quantitative real time PCR. RNA was extracted using RNeasy Mini Kit (Qiagen) following the manufacturer's directions. cDNA was synthesized from $0.5 \mu \mathrm{g}$ RNA using MMLV reverse transcriptase primed with oligo(dT) $(12-18)$, as previously described (Hamby et al., 2006a). Quantitative real-time PCR (qRT-PCR) was performed using a LightCycler 480 (Roche) and LightCycler 480 SW 1.5 software (Roche) using Taqman Probes (Applied Biosystems). Twenty microliter reactions (in $\mathrm{H}_{2} \mathrm{O}$ ) consisted of $2.5 \mu \mathrm{l}$ cDNA, $10 \mu \mathrm{l}$ Taqman Universal Gene Expression Master Mix (Applied Biosystems), and $2 \mu \mathrm{l}$ of a specific Taqman Probe. Taqman probes (Assay ID; Applied Biosytems) were used to detect expression of mouse Gjb2 (Mm00433643_s1), Lif (Mm00434762_g1), Il6 (Mm00446190_m1), Tlr2 (Mm00442346_m1), Ccl5 (Mm01302427_m1), Cxcl1 (Mm04207460_m1),Nos2(Mm00440502_ m1), Sema4a (Mm00443140_m1), Cxcl10 (Mm00445235_m1), Klf2 (Mm01244979_g1), Myd88 (Mm00440338_m1), Gp130 (Mm00439665_ m1), S1pr3 (Mm04229896_m1), Ednrb (Mm00432989_m1), Ednra (Mm01243722_m1), Cxcr4 (Mm01292123_m1), Adra2a (Mm00845383_ s1), Adora1 (Mm01308023_m1), F2rl1 (Mm00433160_m1), P2ry1 (Mm00435471_m1), or the housekeeping gene Gapdh (Mm99999915_g1) for normalization of total cDNA/sample. Cycling conditions were $94^{\circ} \mathrm{C}$ for $10 \mathrm{~min}$, followed by $45 \mathrm{cycles}$ at $95^{\circ} \mathrm{C}$ for $15 \mathrm{~s}$ and $60^{\circ} \mathrm{C}$ for $15 \mathrm{~s}$ with all ramp up/down rates at $1.6^{\circ} \mathrm{C} / \mathrm{s}$. Relative quantification of cDNA was calculated using the comparative cycle threshold $\left(C_{\mathrm{T}}\right)$ method, wherein target $C_{\mathrm{T}}$ levels were normalized to Gapdh $C_{\mathrm{T}}$ values from the same sample (separate wells). The normalized $C_{\mathrm{T}}$ values were then compared with a calibrator value (untreated astrocytes) to determine the relative fold or $\log _{2}$-fold changes in target mRNA levels over the calibrator.

Intracellular calcium imaging. Astrocytes were imaged as described previously (Shigetomi and Khakh, 2009). Briefly, astrocytes were loaded with $2.5 \mu \mathrm{M}$ Fluo-4 AM (Invitrogen) in the presence of $0.05 \%$ 
Pluronic F-127 (20\% solution in dimethylsulfoxide) in physiological buffer for $30 \mathrm{~min}$, then transferred to dye-free buffer for $30 \mathrm{~min}$ before experimentation to allow cleavage of the AM ester group. Physiological buffer consisted of $110 \mathrm{~mm} \mathrm{NaCl}, 5.4 \mathrm{~mm} \mathrm{KCl,} 1.8 \mathrm{~mm}$ $\mathrm{CaCl}_{2}, 0.8 \mathrm{~mm} \mathrm{MgCl}_{2}, 10 \mathrm{~mm}$ D-glucose, and $10 \mathrm{~mm}$ HEPES, adjusted to $\mathrm{pH} 7.40$ using $\mathrm{NaOH}$, in deionized ultrapure water. Fluorescence was captured using an Olympus BX51 or BX61WI microscope with an Olympus $40 \times 0.8 \mathrm{NA}$ water-immersion objective lens and a cooled CCD camera (Imago). Excitation was provided by a Polychrome V or Polychrome IV monochromater (TILL Photonics). The hardware was controlled by a personal computer, an appropriate frame grabber (TILL Photonics), and macros driven by TILLvisION software. Appropriate filters (Chroma Technology) were chosen for Fluo-4 and Fura2 imaging (Glen Spectra). Imaged cells were continually perfused with either physiological buffer alone or containing various GPCR agonists using a custom-made fast solution switcher that was controlled manually or via a digital interface controlling a bank of solenoid valves (Lee Company), both allowing for fast exchange of solutions in seconds (Shigetomi et al., 2012). GPCR agonists used were as follows: uridine $5^{\prime}$-diphosphoglucose disodium salt (UDPGlc; Sigma), Uridine 5'-diphosphogalactose disodium salt (UDPGal; Sigma), 2-chloro-N6-cyclopentyladenosine (CCPA; Tocris Bioscience), guanfacine $\mathrm{HCl}$ (Tocris Bioscience), B-HT 933 (Tocris Bioscience), (-)-epinephrine (Sigma), recombinant mouse CXCL12/SDF-1a (R\&D Systems), IRL1620 (Tocris Bioscience), BQ3020 (Tocris Bioscience), endothelin-1 (Tocris Bioscience), adenosine (Tocris Bioscience), ADP $\beta$ S (Calbiochem), ADP (Sigma), or ATP (Sigma). Data were analyzed using National Institutes of Health ImageJ, Microsoft Excel, and Graphpad Prism software.

siRNA transfection. Astrocytes plated on $12 \mathrm{~mm}$ coverslips in 24 -well plates were transfected with experimental or negative control siRNA using Lipofectamine 2000 (Invitrogen) per manufacturer's instructions. Several hours before transfection, astrocytes were washed with and fed penicillin and streptomycin-free Optimem (Invitrogen). Before transfection, culture medium was removed and $400 \mu \mathrm{l}$ Optimem medium was added. After making the siRNA (40pmol/well) plus Lipofectamine 2000 ( $1 \mu \mathrm{l} /$ well $)$ in Optimem mixture, $100 \mu \mathrm{l}$ was added into each well. Experimental siRNAs used were as follows: Ednrb, EdnrbMSS203783; P2ry1, P2ry1MSS207363; and P2ry14, P2ry14MSS204176 (Stealth Select RNAi siRNA; Invitrogen). Negative control siRNA used was Stealth Select RNAi siRNA Negative Control LO GC (catalog \#12935-200; Invitrogen). Astrocytes were fed with maintenance medium the following day and imaged for calcium measurements $4 \mathrm{~d}$ post-transfection.

In vivo injections of cytokine and endotoxin. All in vivo experiments were conducted using wild-type, male and female C57BL/6 mice from an inhouse breeding colony. Mice were housed in a $12 \mathrm{~h}$ light/dark cycle in a specific pathogen-free facility with controlled temperature and humidity and allowed free access to food and water, and all surgical procedures and experiments were conducted according to protocols approved by the Chancellor's Animal Research Committee of the Office for Protection of Research Subjects at University of California Los Angeles. All surgical procedures were performed under sterile conditions with isoflurane in oxygen-enriched air as the general anesthesia and using an operating microscope (Zeiss) and rodent stereotaxic apparatus (David Kopf) as described previously (Myer et al., 2006). The skull was exposed and a burr hole was drilled with a high-speed dental drill. Solutions of $1 \mu \mathrm{l}$ of sterile PBS or TGF $\beta+$ LPS + IFN $\gamma$ prepared in PBS were injected stereotaxically into the frontal, sensorimotor cortex using the target coordinates of $0.0 \mathrm{~mm}$ anterior to bregma, $1.5 \mathrm{~mm}$ lateral to bregma, and a depth of $0.75 \mathrm{~mm}$ below the cortical surface. Injections were made at a speed of $0.2 \mu \mathrm{l}$ per minute using glass micropipettes (pulled and ground to $25-50 \mu \mathrm{m}$ tips) connected via specialized connectors and highpressure tubing (Kopf) to a $10 \mu$ l syringe (Hamilton) under the control of a microinfusion pump (Harvard Instruments). TGF $\beta+\mathrm{LPS}+\mathrm{IFN} \gamma$ PBS consisted of TGF- $\beta 1(0.3 \mu \mathrm{g} / \mu \mathrm{l}$; human recombinant, R\&D Systems) and LPS ( $2 \mu \mathrm{g} / \mu \mathrm{l}$; E. coli 0127:B8, Sigma) plus IFN $\gamma(0.3 \mu \mathrm{g} / \mu \mathrm{l}$; recombinant mouse, R\&D Systems). Analgesic was given before wound closure and every $12 \mathrm{~h}$ for $48 \mathrm{~h}$ postinjury. No adverse effects were observed.
Immunohistochemistry. After survival times of $1 \mathrm{~d}, 3 \mathrm{~d}$, or $5 \mathrm{~d}$ after forebrain injections, mice received terminal anesthesia by barbiturate overdose and were perfused transcardially with PBS followed by $10 \%$ formalin in PBS. Brains were removed, postfixed overnight, and cryoprotected in buffered $30 \%$ sucrose for at least $2 \mathrm{~d}$. Coronal frozen sections $(40 \mu \mathrm{m})$ were prepared using a cryostat microtome (Leica) and processed for fluorescence immunohistochemistry as described previously (Faulkner et al., 2004; Voskuhl et al., 2009). The following primary antibodies were used: mouse anti-GFAP (1:500; Sigma), rabbit anti-CXCL1 (1:100; Lifespan BioSciences), rabbit anti-CCL7 (1:100; Lifespan BioSciences), goat anti-CXCL10 (1:200; Santa Cruz Biotechnology), rabbit antiIL-6 (1:100; Abcam), and rabbit anti-ADRA2A (1:200; Lifespan BioSciences. Fluorescence immunohistochemistry was performed using secondary antibodies with Alexa 488 (green) (Invitrogen) and Cy5 (red) (Vector Laboratories). The nuclear stain, $4^{\prime}$, $6^{\prime}$-diamidino-2-phenylindole dihydrochloride (DAPI; $2 \mathrm{ng} / \mathrm{ml}$, Invitrogen), was used to label nuclei. Stained sections were examined and photographed using fluorescence and laser scanning confocal microscopy (Zeiss).

\section{Results}

\section{Characterization of genomic analyses}

To identify genome-wide changes in astrocyte gene expression induced by inflammatory mediators, we used well characterized cell cultures of purified astrocyte that are $>99 \%$ astrocytes and essentially free of microglia and other cell types (Hamby et al., 2006b), together with a previously established model of combinatorial stimulation with TGF- $\beta 1$ and LPS + IFN $\gamma$ (Hamby et al., 2006a, 2008, 2010). We used Illumina BeadChip-based microarray profiling to compare genome-wide effects of treating these cultures with TGF- $\beta 1$ alone, LPS + IFN $\gamma$, or all three stimuli (TGF $\beta+$ LPS + IFN $\gamma)$ combined, relative to basal (untreated) astrocytes. Raw and normalized data have been deposited in NCBI's Gene Expression Omnibus (Edgar et al., 2002) and are accessible through GEO Series accession number GSE36089 (http://www.ncbi.nlm.nih.gov/geo/query/acc.cgi? $\mathrm{acc}=$ GSE36089). Hierarchical clustering (Fig. 1A) highlighted a high degree of similarity among $n=4$ independent samples from distinct astrocyte cultures within each given treatment group, thereby demonstrating that the changes in gene expression were due to the specific treatment conditions and not due to culture-toculture variability. In addition, we assessed the purity of the astrocyte cultures used for gene array analysis by examining eight probes from the microarrays for three genes selectively associated with microglia-Ibal (three probes, 1212938, 1218123, and 2804487), Emr1/ F4/80 (three probes, 1216880, 2756353, and 2847787), and Csf1r/cfms (two probes, 1230485 and 2710819) —and found expression levels compatible with low or no expression, as well as no significant differences among any of the probes in any of the three treatment conditions TGF- $\beta 1$, LPS + IFN $\gamma$, or TGF $\beta+$ LPS + IFN $\gamma$. We further conducted RT-PCR for the microglial marker, Ibal, and found no detectable bands in any of the three treatment conditions in contrast with bands obtained from positive control samples (data not shown). Together these findings confirm both the integrity of our basic experimental protocol and the absence of microglial contamination from the purified astrocyte cultures examined for the present study.

\section{Treatment-dependent global changes in gene expression profiles}

We began our data evaluations by characterizing the global changes in gene expression induced by the different treatment conditions-TGF- $\beta 1$ alone, LPS + IFN $\gamma$, or TGF $\beta+$ LPS + IFN $\gamma$ - each compared with untreated (basal) astrocytes, using a stringent criterion of significance that corrects for multiple test- 
A

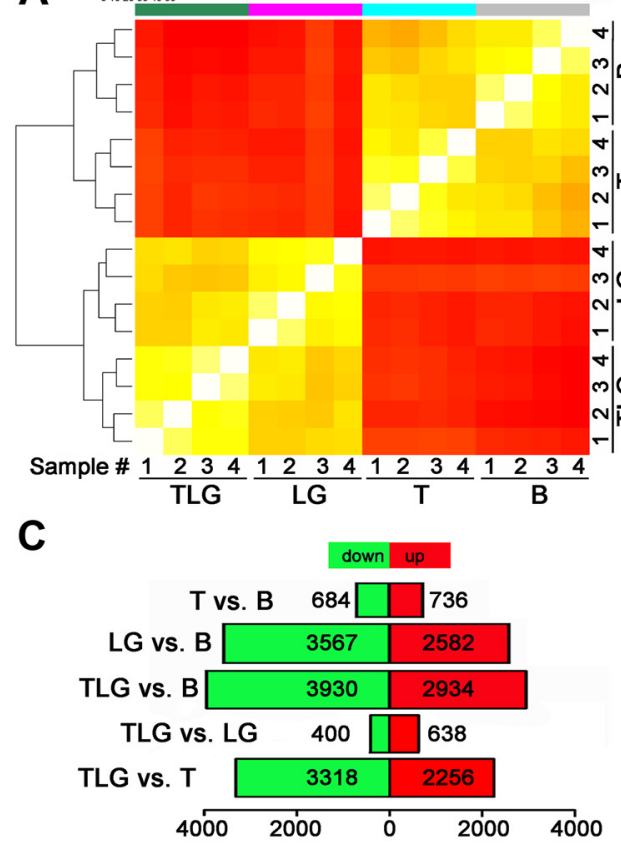

NUMBER OF GENE PROBES (DOWN AND UP)

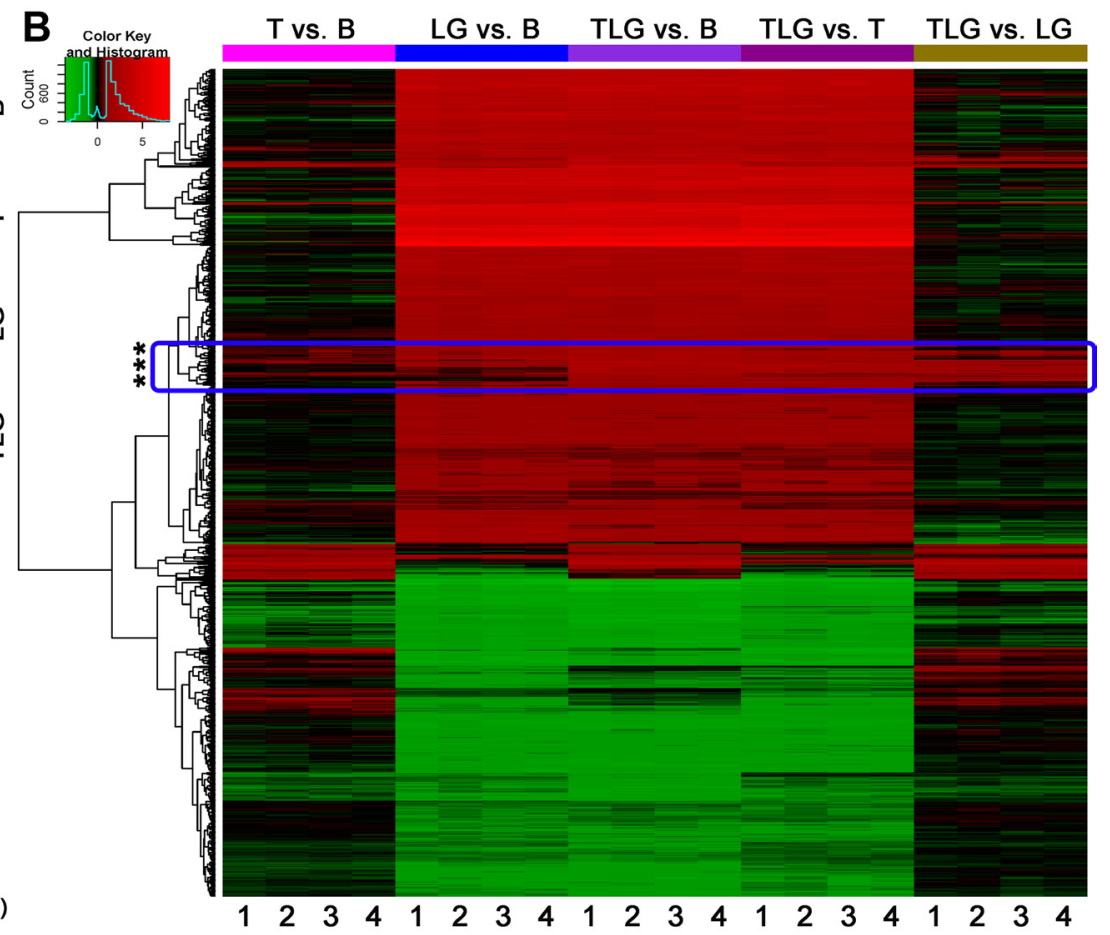

D

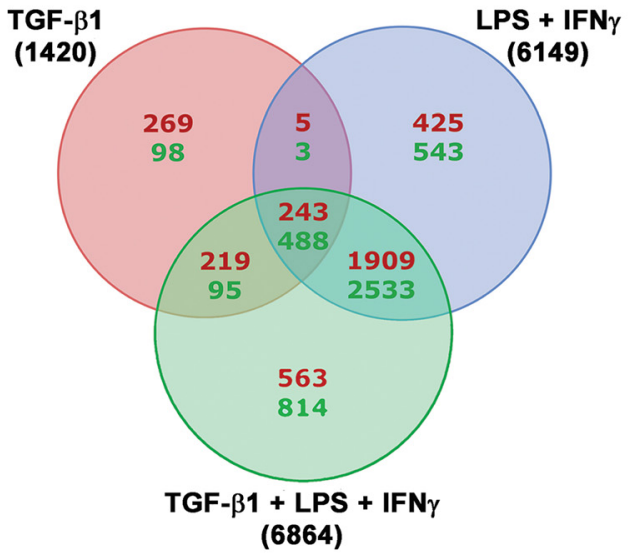

\section{E Filtering Strategy}

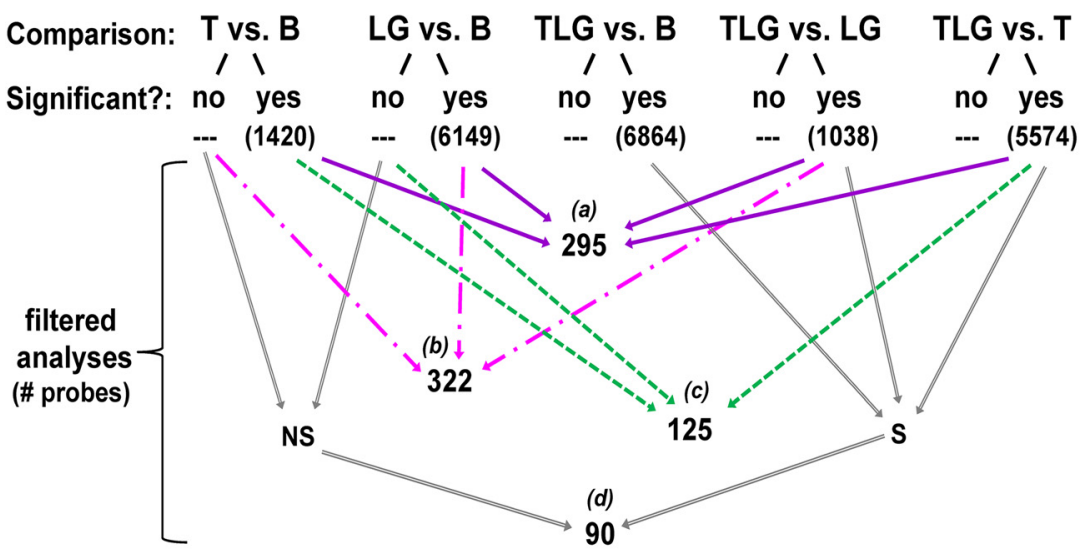

\section{F Categories of Gene Regulation}

\begin{tabular}{|c|c|c|c|c|c|}
\hline Category & $\mathbf{T}$ & LG & $\begin{array}{l}\text { Total \# probes in } \\
\text { category }\end{array}$ & $\begin{array}{c}\text { TLG additive changes } \\
\text { (\# probes) }\end{array}$ & $\begin{array}{c}\text { TLG synergistic changes } \\
\text { (\# probes) }\end{array}$ \\
\hline a & change & change & 295 & 243 & 52 \\
\hline b & no change & change & 322 & 142 & 180 \\
\hline c & change & no change & 125 & 65 & 60 \\
\hline d & no change & no change & 90 & - & 90 \\
\hline \multicolumn{5}{|c|}{ Total \# probes indicating gene regulation in a synergistic manner } & 382 \\
\hline \multicolumn{6}{|c|}{$\begin{array}{l}\text { change }=F D R \leq 0.05,0.20 \log _{2} \text { ratio cutoff; no change }=F D R>0.05 \text {. Total } \# \text { column values derived from filtering as shown in } \\
\text { Fig. } 1 E \text {. Categories a-c, TLG treatment was deemed additive when T/B }+L G / B=T L G / B \text { or exhibited less than } 0.30 \text { log } 2 \\
\text { change; Non-additive or synergistic interactions were determined as follows: }(a): T / B+L G / B \neq T L G / B \text { and exhibited difference } \\
\text { greater than } 0.30 \log _{2} \text { change. (b) TLG/B }-L G / B>0.30 \text { log2 fold ratio. (c) TLG/B }-T / B>0.30 \text { log2 fold ratio. For } d \text {, all were } \\
\text { deemed synergistic from Fig. } 1 E \text { filtering Abbreviations: } T=T G F-\beta 1, L G=L P S+I F N \gamma, T L G=T G F-\beta 1+L P S+I F N \gamma\end{array}$} \\
\hline
\end{tabular}

Figure 1. Effects on astrocyte genomic profiles of treatment with TGF- $\beta 1, L P S+I F N \gamma$, or all three stimuli combined. $A$, Gene array clustering of the top 1000 most variable genes shown as a colored heatmap depicting the MAD value for each interarray comparison for samples 1-4 for each treatment in astrocytes as indicated. B, basal; T, TGF- $\beta 1$; LG, LPS+IFN $\gamma$; TLG, TGF$\beta 1+$ LPS + IFN $\gamma$. The color map key (top left) represents a low MAD value indicating very little variability (yellow) between comparisons whereas red represents a high MAD value indicating greater differences between comparisons. Dendrogram indicates clustering of samples and treatments based on similarity. $\boldsymbol{B}$, Heatmap indicating significant changes (FDR $p$ value $\leq 0.05$ ) in gene expression (black, no change; red, increase; green, decrease) due to TGF- $\beta 1$ (Tvs B), LPS + IFN $\gamma($ LG vs B), and TGF- $\beta 1+$ LPS + IFN $\gamma$ (TLG vs B), compared with basal astrocytes, (Figure legend continues.) 
Table 1. Top upregulated and downregulated genes

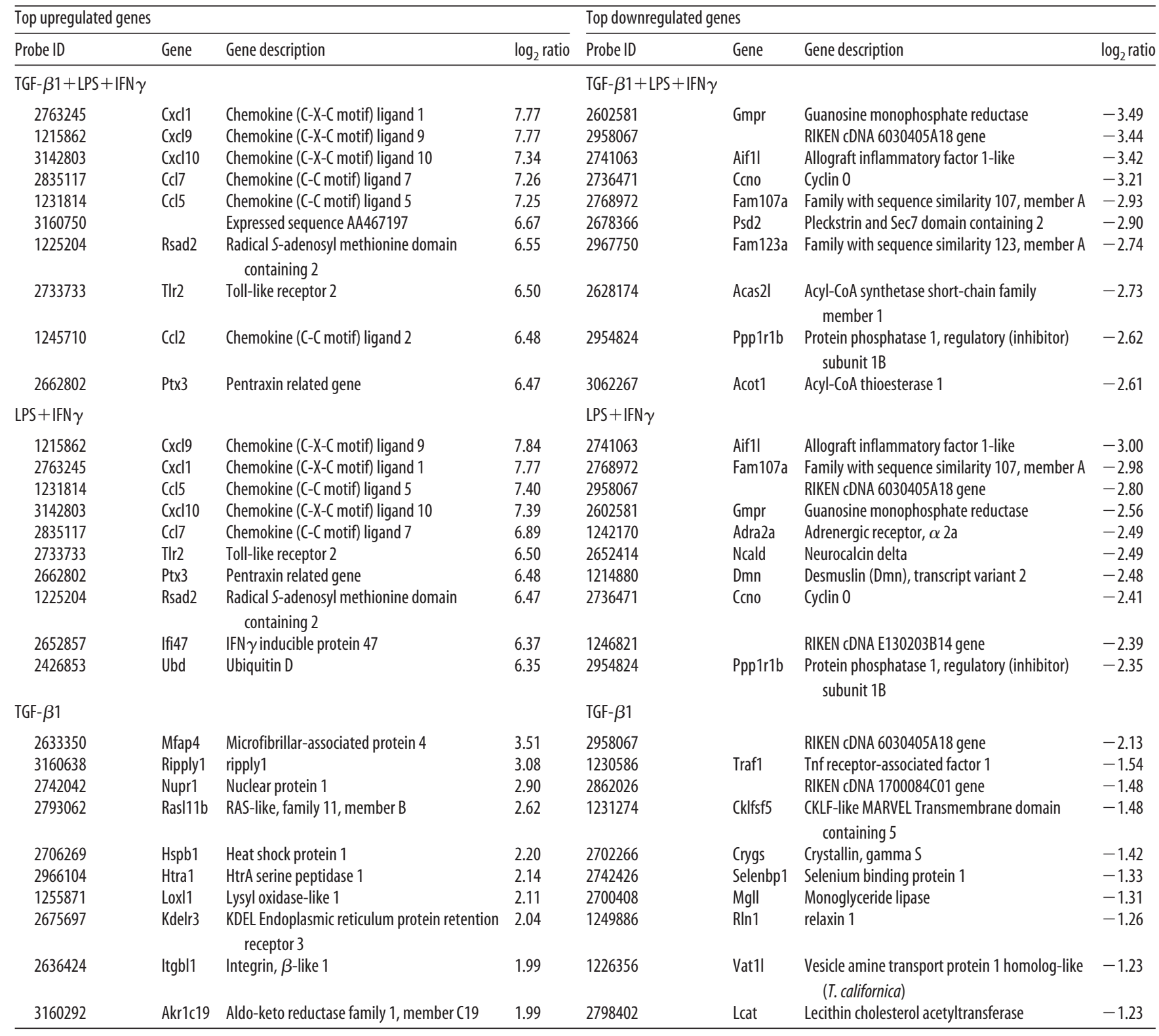

All probes start with ILMN. FDR $\leq 0.05,0.02$ absolute $\log _{2}$ ratio cutoff.

ing using a FDR of $<0.05$. These analyses revealed that largescale changes in gene expression occurred as a result of treatment with either LPS + IFN $\gamma$ (6149 differentially expressed probes) or

\footnotetext{
(Figure legend continued.) as well as TLG vs Tand TLG versus LG. Genes are clustered by similarity. Boxed region denoted by asterisks indicates examples of genes that behaved differently across different treatment conditions. $C$, Total number of genes significantly (FDR $p \leq 0.05$ ) altered (up, red; down, green) by each treatment comparison. $\boldsymbol{D}$, Venn diagram depicts the number of genes changed in a treatment-specific and nonspecific manner. Within each segment, upper red numerical values $=$ number of genes upregulated. Lower green numerical values $=$ number of genes downregulated. Total numbers of genes changed are labeled outside of the Venn diagram beside its respective circle's treatment condition. $\boldsymbol{E}$, Flow chart depicting filtering strategy conducted using statistical cutoffs to generate subsequent datasets for analysis. Numbers indicate number of probes within each filtered dataset and $a-d$ demarcate the four new dataset categories for subsequent analysis. $S$, significant; $\mathrm{NS}$, nonsignificant. $\boldsymbol{F}$, Categories of additive and synergistic treatment interactions emerging from filtering strategy in $\boldsymbol{E}$. All categories a-d had a further change from either $\mathrm{T}(\mathrm{c})$ or $\mathrm{LG}(\mathrm{b})$ or both $(\mathrm{a}, \mathrm{d})$ due to TLG treatment. Numbers of gene probes are shown indicating additive or synergistic gene regulation by TLG treatment per category. $\boldsymbol{A}-\boldsymbol{E}, n=4$ independent samples from distinct astrocyte cultures.
}

TGF $\beta+$ LPS + IFN $\gamma(6864)$ relative to basal (untreated) astrocytes, whereas treatment with TGF- $\beta 1$ alone (1420) induced relatively fewer changes (Fig. $1 B-E$ ). All three stimulation conditions elicited approximately proportionate changes with respect to the number of upregulated genes (TGF- $\beta 1,736$; LPS + IFN $\gamma$, 2582; TGF $\beta+$ LPS + IFN $\gamma$, 2934) versus downregulated genes $($ TGF- $\beta 1,684$; LPS+IFN $\gamma, 3567 ;$ TGF $\beta+$ LPS + IFN $\gamma, 3930)$ (Fig. 1C). Importantly, while some genes were altered (up or down) by only one treatment in a treatment-specific manner, others were consistently altered across two or all three of the treatments (Fig. $1 B, D$ ).

\section{Greatest fold changes in specific genes}

To identify the most highly regulated genes, we sorted the list of gene probes according to the greatest $\log _{2}$-fold changes in gene expression (FDR $p \leq 0.05$ ) induced by each of the three treatment conditions relative to basal. Table 1 shows the top 10 genes with the greatest $\log _{2}$ fold increases and decreases in expression for each treatment condition, 
Table 2. Types of synergistic interactions and example genes

\begin{tabular}{lllll}
\hline $\begin{array}{l}\text { Synergistic } \\
\text { category* }\end{array}$ & T & LG & TLG & Example genes \\
\hline$d$ & No change & No change & Up & Itga5, Bmp1, Tgfb1, Homer1, Rims3, Pi4k2b \\
$d$ & No change & No change & Down & Dtx4, Tmem53 \\
b & No change & Up & Further up & Il6, Lif, Gdnf, Nos2, Sod3, Sema4a, Egr2, Cc18, Ccl12, Gpr83, Gjb2, Slc16a9, Casp8 \\
b & No change & Up & Down (relative to LG) & Calb2, Klf2, Brip1, Ptges, \\
b & No change & Down & Further down & Itpk1, Gpr23 \\
b & No change & Down & Up (relative to LG) & Adora1, Gpr156, Fgf12, Ctgf, SIc4a2, \\
c & Up & No change & Further up & Ccl17, Col12a1, Eln, Lox \\
c & Up & No change & Down (relative to T) & Igf1, Cav1, Sema7a, Cd28, Slc7a5, \\
c & Down & No change & Up (relative to T) & Thbs1, Foxp1 \\
a & Up & Up & Further up & I111, Cxcl16, P2ry6, P2ry14, Pdgfb, Dok1 \\
\hline
\end{tabular}

Change: FDR $\leq 0.05,0.02$ absolute $\log _{2}$ ratio cutoff; no change: FDR $>0.05$. T, TGF- $\beta 1$; LG, LPS + IFN $\gamma$; TLG, TGF- $\beta 1+$ LPS + IFN $\gamma$. *, See categories in Figure $1 F$.

TGF- $\beta 1$, LPS + IFN $\gamma$, or TGF $\beta+$ LPS + IFN $\gamma$, relative to basal. It is noteworthy that 7 of the top 10 genes that were most highly upregulated by combinatorial treatment with TGF $\beta+\mathrm{LPS}+\mathrm{IFN} \gamma$ encode molecules involved in immune and inflammatory processes, namely the chemokines, $C x c l 1, C x c l 9, C x c l 10, C c l 2, C c l 5$, and $C c l 7$ and the toll-like receptor, $\operatorname{Tlr} 2$ (Table 1).

\section{Synergistic effects of combinatorial treatment}

We next asked whether gene regulatory changes in the combinatorial treatment group, TGF $\beta+\mathrm{LPS}+\mathrm{IFN} \gamma$, were simply the sums of the effects of TGF- $\beta 1$ treatment and LPS + IFN $\gamma$ treatment, or whether there were additional effects due to synergistic combinatorial interactions. To examine the gross extent of change, we examined heat maps that represented the number of genes changed by TGF- $\beta 1$ versus basal, LPS + IFN $\gamma$ versus basal, TGF $\beta+$ LPS + IFN $\gamma$ versus basal, TGF $\beta+$ LPS + IFN $\gamma$ versus TGF- $\beta 1$, and TGF $\beta+\mathrm{LPS}+\mathrm{IFN} \gamma$ versus LPS $+\mathrm{IFN} \gamma$ (Fig. $1 B$ ). This comparison indicated at a gross level that there were subsets of genes that behaved differently across conditions (Fig. $1 B$, boxed region denoted by asterisks). Further analyses of these comparisons using an $\operatorname{FDR} p \leq 0.05$ revealed that substantial numbers of genes were altered by TGF $\beta+$ LPS + IFN $\gamma$ versus TGF- $\beta 1$ (5574 total) or by TGF $\beta+\mathrm{LPS}+\mathrm{IFN} \gamma$ versus LPS + IFN $\gamma$ (1038 total), in comparison with genes regulated by TGF $\beta+\mathrm{LPS}+\mathrm{IFN} \gamma$ versus basal (6864) or LPS + IFN $\gamma$ versus basal (6149) or TGF- $\beta 1$ versus basal (1420) (Fig. $1 E$ ). These findings suggested the potential for combinatorial treatment interactions in which treatment with TGF $\beta+$ LPS + IFN $\gamma$ might lead to substantial changes in gene expression relative to treatment with either TGF- $\beta 1$ or LPS + IFN $\gamma$ alone.

To dissect the nature of these potential combinatorial treatment interactions, we first determined how many gene probes were modulated significantly (FDR $\leq 0.05)$ by combinatorial treatment in either the up or down direction relative to the individual treatments, regardless of whether or not the combinatorial effects were additive or synergistic. To simplify this analysis, we grouped gene probes into four categories $(a-d)$ for evaluation based on whether individual treatments had $($ FDR $\leq 0.05)$ or had not $($ FDR $>0.05)$ caused significant changes in gene expression (Fig. $1 E a-d, F a-d$ ). In this manner we identified (a) 295 gene probes in which TGF- $\beta 1$ and LPS + IFN $\gamma$ had both caused significant changes versus basal (Fig. $1 E a$ ); (b) 322 gene probes in which TGF- $\beta 1$ had not, and LPS + IFN $\gamma$ had, caused significant changes versus basal (Fig. $1 E b)$; (c) 125 gene probes in which TGF- $\beta 1$ had but LPS + IFN $\gamma$ had not caused significant changes versus basal (Fig. $1 E c$ ); and (d) 90 gene probes in which neither TGF- $\beta 1$ nor LPS+IFN $\gamma$ had caused significant changes versus basal (Fig. $1 E d)$; where in all of these cases $(\mathrm{a}-\mathrm{d})$ the combinatorial treatment had caused significant changes relative to the individual treatments (Fig. $1 E a-d$; Fig. $1 E$, filtering criteria). To determine which of these combinatorial treatment interactions reflected changes that were additive or synergistic, we further dissected the subsets of genes in categories a-d (Fig. $1 F)$. Within the four categories, we identified substantial numbers of gene probes that exhibited either additive or synergistic combinatorial treatment interactions, with a conservative estimate of a total of $>380$ genes that were synergistically modulated in either the up or down direction by combinatorial treatment with TGF $\beta+\mathrm{LPS}+\mathrm{IFN} \gamma$ relative to individual treatments alone (Fig. $1 \mathrm{Fa}-\mathrm{d}$ ). It is noteworthy that these synergistic interactions consisted of different types of gene expression regulation that could not be predicted on the basis of summing the effects of individual stimulators alone. For example, in 90 cases (category d), significant changes in gene expression occurred due to combinatorial treatment with TGF $\beta+\mathrm{LPS}+\mathrm{IFN} \gamma$, even though treatment with TGF- $\beta 1$ alone and LPS + IFN $\gamma$ alone caused no significant change (Fig. $1 F d)$. In other cases combinational stimulation with TGF $\beta+$ LPS + IFN $\gamma$ either significantly augmented or attenuated, or in some cases reversed, changes induced by individual treatments (Table 2). Prototypical genes within each category are listed in Table 2.

\section{qRT-PCR validation of microarray genomic profiling}

To test the validity of the large-scale changes in gene expression found using the Illumina BeadChip-based microarray profiling, we generated new samples of astrocytes for all treatment conditions and used qRT-PCR to evaluate several highly regulated genes, Cxcl1, Ccl5, Cxcl10, and Tlr2 (Table 1). We found similar changes in mRNA expression to those found via microarray analysis for all genes examined (Fig. 2). To validate the synergistic effects of combinatorial treatment revealed by genome-wide microarray profiling, we used qRT-PCR to evaluate various genes synergistically induced by treatment with TGF $\beta+\mathrm{LPS}+\mathrm{IFN} \gamma$ compared with individual treatments, Il6, Lif, Gjb2, Nos2, Sema4a, Klf2, and Myd88 (Table 2) and found similar changes in mRNA expression to those found via microarray analysis for all genes examined (Fig. 2). In addition, we examined a gene whose expression was not significantly altered in any treatment condition in the microarray profiling, Gp130, and found that qRT-PCR results confirmed that there was no change in mRNA expression in any treatment condition relative to basal (Fig. 2). 


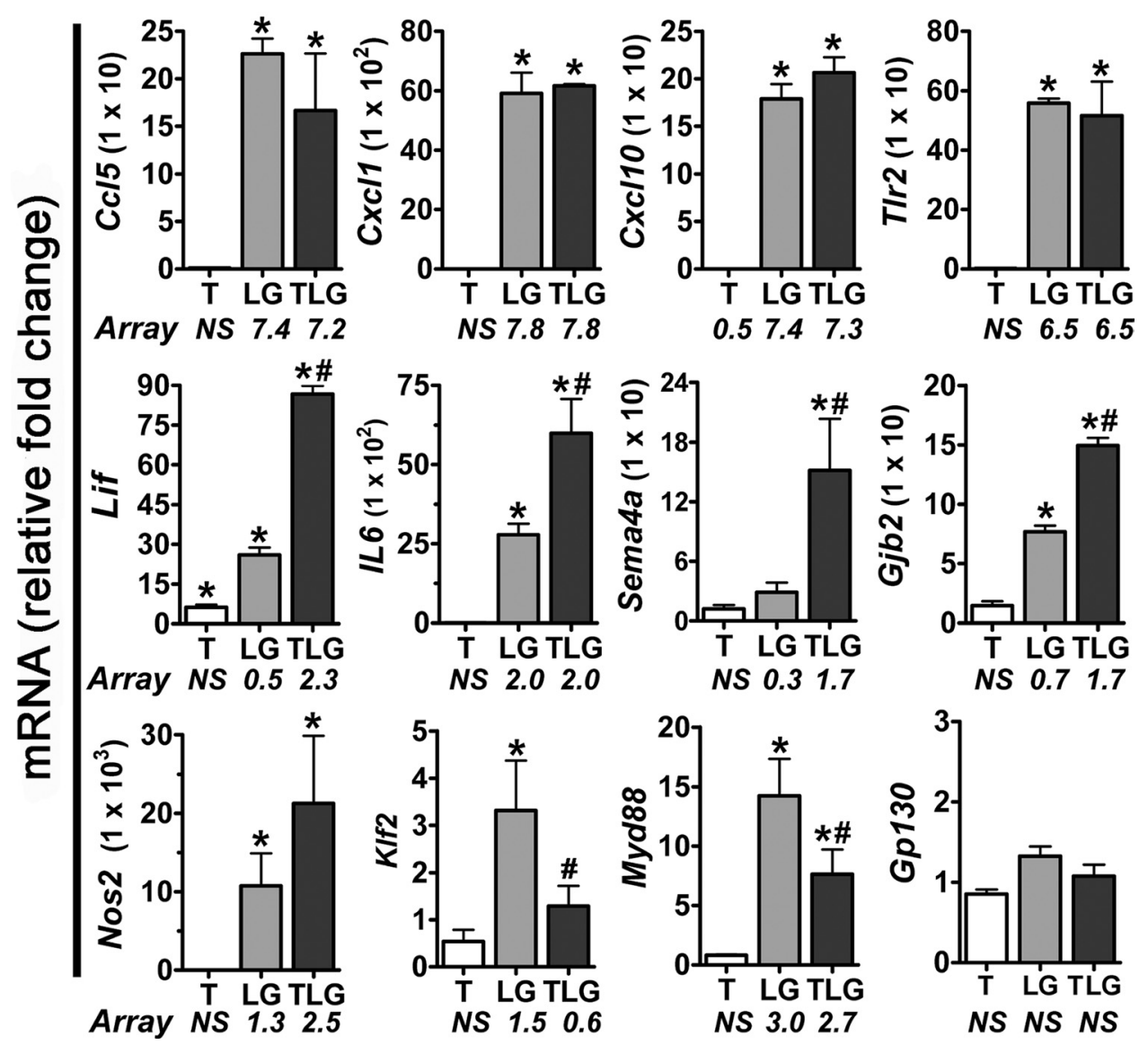

Figure 2. qRT-PCR validation of microarray data. qRT-PCR was performed on untreated or treated (T, TGF- $\beta 1 ; \mathrm{LG}, \mathrm{LPS}+\mathrm{IFN} \gamma$; TLG, TGF- $\beta 1+\mathrm{LPS}+\mathrm{IFN} \gamma)$ primary mouse astrocytes. Fold change in mRNA expression was calculated relative to basal after normalization of expression to GAPDH. Data were expressed as mean relative fold change in $\mathrm{mRNA} \pm$ SEM ( $n=3$ from samples independently generated from that in Fig. 1). ${ }^{*}$, Indicates a significant fold increase compared with basal, whereas \# indicates a significant difference in TLG-treated astrocytes compared with LG $(p \leq 0.05)$ as assessed via repeated-measures ANOVA after normalizing data followed by Newman-Keuls multiple-comparison test. Significantly altered (FDR $\leq 0.05)$ microarray log 2 ratios are provided below treatment-labeled bars.

Table 3. Top 5 Associated Networks

\begin{tabular}{|c|c|c|c|c|c|c|c|c|}
\hline \multicolumn{3}{|l|}{$\overline{\mathrm{TGF}-} \beta 1+\mathrm{LPS}+\mathrm{IFN} \gamma$} & \multicolumn{3}{|l|}{$\mathrm{LPS}+\mathrm{IFN} \gamma$} & \multicolumn{3}{|l|}{ TGF- $\beta 1$} \\
\hline Top networks & Score & $\begin{array}{l}\text { Focus } \\
\text { mol. }\end{array}$ & Top networks & Score & $\begin{array}{l}\text { Focus } \\
\text { mol. }\end{array}$ & Top networks & Score & $\begin{array}{l}\text { Focus } \\
\text { mol. }\end{array}$ \\
\hline Antigen presentation, cell death & 18 & 35 & $\begin{array}{l}\text { Cell death, cell cycle, organismal injury and } \\
\text { abnormalities }\end{array}$ & 20 & 35 & $\begin{array}{l}\text { Cellular development, cellular growth and } \\
\text { proliferation }\end{array}$ & 30 & 31 \\
\hline $\begin{array}{l}\text { Cell morphology, cellular compromise, DNA } \\
\text { replication, recombination, and repair }\end{array}$ & 18 & 35 & $\begin{array}{l}\text { Lipid metabolism, small molecule } \\
\text { biochemistry, vitamin and mineral } \\
\text { metabolism }\end{array}$ & 20 & 35 & $\begin{array}{l}\text { Lipid metabolism, small molecule } \\
\text { biochemistry, vitamin and mineral } \\
\text { metabolism }\end{array}$ & 30 & 31 \\
\hline $\begin{array}{l}\text { Post-translational modification, cell } \\
\text { morphology, cellular assembly and } \\
\text { organization }\end{array}$ & 18 & 35 & $\begin{array}{l}\text { Organismal injury and abnormalities, cell } \\
\text { morphology, cellular assembly and } \\
\text { organization }\end{array}$ & 20 & 35 & Cell death, genetic disorder & 28 & 30 \\
\hline Gastrointestinal disease, hepatic disease & 16 & 34 & Cell death, gene expression, cellular compromise & 18 & 34 & Cellular growth and proliferation, cancer & 25 & 28 \\
\hline
\end{tabular}

Top associated networks from the from the IPA (Ingenuity) library most significant to our microarray dataset of significantly altered genes (FDR $\leq 0.05,0.20 \log _{2}$ ratio cutoff). Top 3 Networks for TGF- $\beta 1+$ LPS + IFN $\gamma$ are shown in detail in Figure 3. $p$ values were calculated using a right-tailed Fisher's exact test. Score $=$ negative $\log$ of $p$ value. Networks with scores of 2 or greater have at least a $99 \%$ confidence of not being generated by random chance alone.

Bioinformatic analyses of molecular networks, functions, and pathways

We next used the Ingenuity Pathway Analysis software (Ingenuity Systems) to identify functional molecular groupings within our datasets of differentially regulated genes, based on their statistical association with known Associated Network Functions,
Molecular and Cellular Functions, and Canonical Pathways in the Ingenuity knowledge base. For this analysis, we used a conservative threshold and selected genes with an absolute $\log _{2}$ fold change of at least 0.20 , and an FDR corrected $p$ value $\leq 0.05$. Table 3 shows the top five Associated Network Functions, Table 4 the top five Molecular and Cellular Functions, and Table 5 the top 20 
Table 4. Top five IPA Molecular and Cellular Functions

\begin{tabular}{|c|c|c|c|c|c|}
\hline \multicolumn{2}{|l|}{$\overline{\mathrm{TGF}-\beta 1+\mathrm{LPS}+\mathrm{IFN} \gamma}$} & \multicolumn{2}{|l|}{$\mathrm{LPS}+\mathrm{IFN} \gamma$} & \multicolumn{2}{|l|}{ TGF- $\beta 1$} \\
\hline Category & $p$ value & Category & $p$ value & Category & $p$ value \\
\hline Cell death & $7.49 \times 10^{-13}$ & Cell death & $3.57 \times 10^{-9}$ & Cellular development & $1.07 \times 10^{-6}$ \\
\hline Cellular assembly and organization & $1.26 \times 10^{-9}$ & Post-translational modification & $7.21 \times 10^{-9}$ & Lipid metabolism & $2.18 \times 10^{-5}$ \\
\hline Cellular function and maintenance & $1.26 \times 10^{-9}$ & Cellular assembly and organization & $8.40 \times 10^{-9}$ & Small molecule biochemistry & $2.18 \times 10^{-5}$ \\
\hline Post-translational modification & $1.79 \times 10^{-9}$ & Cellular function and maintenance & $8.40 \times 10^{-9}$ & Vitamin and mineral metabolism & $2.18 \times 10^{-5}$ \\
\hline Cellular growth and proliferation & $1.04 \times 10^{-8}$ & Cellular growth and proliferation & $4.44 \times 10^{-9}$ & Cellular movement & $2.78 \times 10^{-5}$ \\
\hline
\end{tabular}

Molecular and cellular functions from the IPA (Ingenuity) library most significant to our microarray dataset of significantly altered genes (FDR $\leq 0.05,0.20 \log _{2}$ ratio cutoff). $p$ values were calculated using a right-tailed Fisher's exact test.

Table 5. Top 20 IPA Canonical Pathways

\begin{tabular}{|c|c|c|c|c|c|c|c|c|}
\hline \multicolumn{3}{|l|}{ TGF- $\beta 1+$ LPS + IFN $\gamma$} & \multicolumn{3}{|l|}{ LPS + IFN $\gamma$} & \multicolumn{3}{|l|}{ TGF- $\beta 1$} \\
\hline Ingenuity canonical pathways & $\begin{array}{l}-\log \\
\text { ( } p \text { value })\end{array}$ & Ratio & Ingenuity canonical pathways & $\begin{array}{l}-\log \\
\text { ( } p \text { value })\end{array}$ & Ratio & Ingenuity canonical pathways & $\begin{array}{l}-\log \\
\text { ( } p \text { value })\end{array}$ & Ratio \\
\hline Activation of IRF by cytosolic PRRs & 9.05 & 0.56 & Molecular mechanisms of cancer & 8.33 & 0.38 & RhoA signaling & 4.18 & 0.18 \\
\hline CD40 signaling & 8.83 & 0.62 & TNFR1 signaling & 7.99 & 0.60 & Wnt $/ \beta$-catenin signaling & 2.99 & 0.14 \\
\hline Role of IL-17A in arthritis & 8.63 & 0.62 & $4-1 \mathrm{BB}$ signaling in T-lymphocytes & 7.91 & 0.70 & Human embryonic stem cell Pluripotency & 2.96 & 0.14 \\
\hline IL-1 signaling & 8.62 & 0.55 & TNFR2 signaling & 7.91 & 0.70 & biosynthesis of steroids & 2.84 & 0.29 \\
\hline Toll-like receptor signaling & 8.37 & 0.67 & LPS-stimulated MAPK signaling & 7.77 & 0.54 & Caveolar-mediated endocytosis signaling & 2.49 & 0.15 \\
\hline CD27 Signaling in lymphocytes & 8.32 & 0.63 & Activation of IRF by cytosolic PRRs & 7.30 & 0.50 & Sulfur metabolism & 2.46 & 0.25 \\
\hline Type I diabetes mellitus signaling & 8.23 & 0.50 & CD27 signaling in lymphocytes & 7.27 & 0.57 & ILK signaling & 2.34 & 0.12 \\
\hline LPS-stimulated MAPK signaling & 8.16 & 0.58 & Toll-like receptor signaling & 7.24 & 0.61 & Factors promoting cardiogenesis in vertebrates & 2.25 & 0.15 \\
\hline IL-17 signaling & 8.15 & 0.61 & Induction of apoptosis by HIV1 & 7.11 & 0.55 & Integrin signaling & 2.07 & 0.11 \\
\hline IL-17A signaling in fibroblasts & 8.09 & 0.69 & Type I diabetes mellitus signaling & 6.87 & 0.45 & Mitotic roles of polo-like kinase & 1.97 & 0.15 \\
\hline 4-1BB signaling in T-lymphocytes & 8.03 & 0.73 & Apoptosis signaling & 6.82 & 0.50 & Actin cytoskeleton signaling & 1.89 & 0.10 \\
\hline $\begin{array}{l}\text { Role of MØs, fibroblasts and endo. } \\
\text { cells in RA }\end{array}$ & 7.79 & 0.41 & Type II diabetes mellitus signaling & 6.63 & 0.43 & $\operatorname{PPAR} \alpha / \operatorname{RXR} \alpha$ activation & 1.80 & 0.11 \\
\hline HMGB1 signaling & 7.77 & 0.54 & Interferon signaling & 6.51 & 0.62 & Endothelin-1 signaling & 1.80 & 0.12 \\
\hline IL-6 signaling & 7.52 & 0.54 & NF- $\kappa$ B signaling & 6.51 & 0.42 & Propanoate metabolism & 1.79 & 0.16 \\
\hline $\mathrm{NF}-\kappa \mathrm{B}$ signaling & 7.27 & 0.46 & TWEAK signaling & 6.44 & 0.61 & Agrin interactions at neuromuscular junction & 1.76 & 0.15 \\
\hline ATM signaling & 7.17 & 0.65 & IL-17A signaling in fibroblasts & 6.42 & 0.62 & $\begin{array}{l}\text { Role of MAPK signaling in the pathogenesis of } \\
\text { influenza }\end{array}$ & 1.76 & 0.16 \\
\hline Induction of apoptosis by HIV1 & 7.16 & 0.59 & Acute phase response signaling & 6.16 & 0.43 & Cdc42 signaling & 1.73 & 0.09 \\
\hline Dendritic cell maturation & 7.06 & 0.39 & Death receptor signaling & 6.10 & 0.52 & Selenoamino acid metabolism & 1.68 & 0.19 \\
\hline TNFR2 signaling & 7.02 & 0.70 & Role of RIG1-like Rs in antiviral inn. immunity & 6.03 & 0.46 & Regulation of actin-based motility by Rho & 1.62 & 0.13 \\
\hline TNFR1 signaling & 6.88 & 0.60 & IL-1 signaling & 6.00 & 0.47 & Circadian rhythm signaling & 1.61 & 0.18 \\
\hline
\end{tabular}

PRRs, pattern recognition receptors; Rs, receptors; sig, signaling; RA, rheumatoid arthritis; Møs, macrophages; inn., innate. Canonical pathways from the IPA (Ingenuity) library with the greatest association to our dataset of altered genes ( $F D R \leq 0.05,0.20 \log _{2}$ ratio cutoff) by T, LG, and TLG compared to basal astrocytes are shown in order of greatest association $[-\log (p$ value) $] . p$ values were determined via Fisher's exact test and ratios $=$ the number of genes from our microarray dataset that map to a pathway divided by the total number of molecules that map to that pathway.

Canonical Pathways, that were significantly altered in each of the three treatment conditions. Comparisons across the different treatment groups indicated pronounced differences, particularly between combinatorial treatment with TGF $\beta+$ LPS + IFN $\gamma$ and treatment with TGF- $\beta 1$ alone. Recurrent themes among the Associated Network Functions and Molecular and Cellular Functions that were highly modulated by all three treatment conditions included cell death, cell compromise, and cell injury, as well as regulation of cell morphology, cell organization, cell maintenance, cell growth, and cell proliferation (Tables 4, 5). In addition, it is noteworthy that in the combinatorial treatment group, TGF $\beta+$ LPS + IFN $\gamma$, the most highly regulated network function was antigen presentation, and that all of the top 6 , and 17 of the top 20 Canonical Pathways were related directly to immune or inflammatory signaling (Table 5).

To gain an appreciation of individual genes that were highly regulated in the up or down direction by combinatorial treatment with TGF $\beta+$ LPS + IFN $\gamma$, we next examined the specific gene sets that comprised certain Associated Network Functions and Canonical Pathways. Due to space limitations, only selected examples are shown. We focused particularly on networks and pathways associated with immune and inflammatory signaling, regulation of cell compromise, death, growth, and proliferation that had been identified above as the main general themes represented in our analysis. These themes are heavily represented among the top three most regulated Associated Network Functions, which include Antigen Presentation and Cell Death (Fig. 3A); Cell Morphology, Compromise, and DNA Replication, Recombination, and Repair (Fig. 3B); and Genetic Disorder and Neurological Disease (Fig. 3C). The themes of immune and inflammatory signaling overwhelmingly dominated the most highly regulated Canonical Pathways (Table 5), illustrative examples of which include CD40 Signaling (Fig. 4A), IL-1 Signaling (Fig. 4B), and Chemokine Signaling (Fig. 4C). Inspection of these networks and pathways indicated that individual genes highly regulated by our combinatorial treatment with TGF $\beta+\mathrm{LPS}+\operatorname{IFN} \gamma$ included a wide variety of chemokines, cytokines, growth factors, and intercellular and intracellular signaling molecules, as well as diverse structural and regulatory molecules (Figs. 3, 4).

\section{Regulation of specific genes in recognized functional categories}

To further our understanding of the effects of all of our treatment conditions on specific genes, we next identified specific gene members according to commonly recognized functional molecular categories. We focused on categories broadly related to the main functional themes identified by the bioinformatic analysis described above and on categories relevant to astrocyte biology, and included also certain genes that exhib- 


\section{A Antigen Presentation and Cell Death}

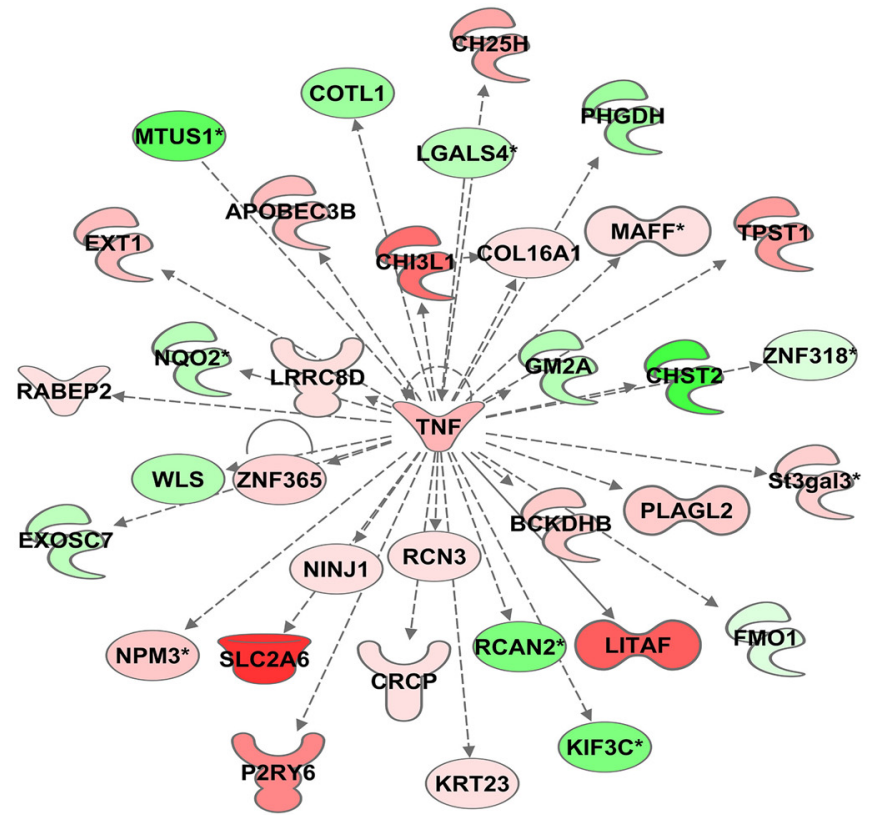

C Genetic Disorder and Neurological Disease

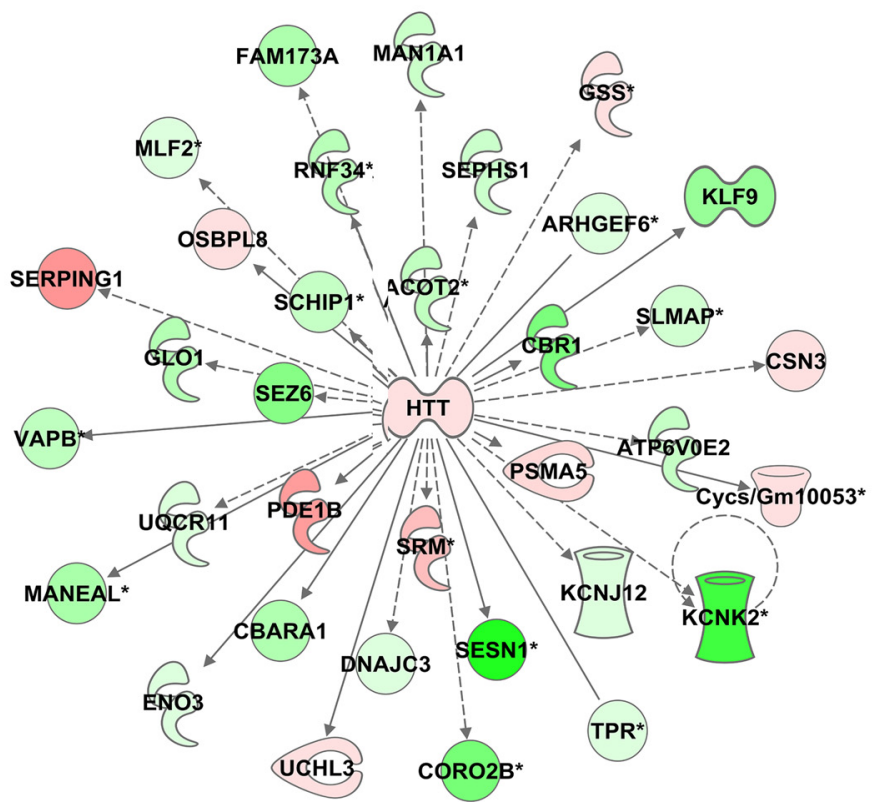

\section{B Cell Morphology, Cellular Compromise, and DNA Replication, Recombination and Repair}

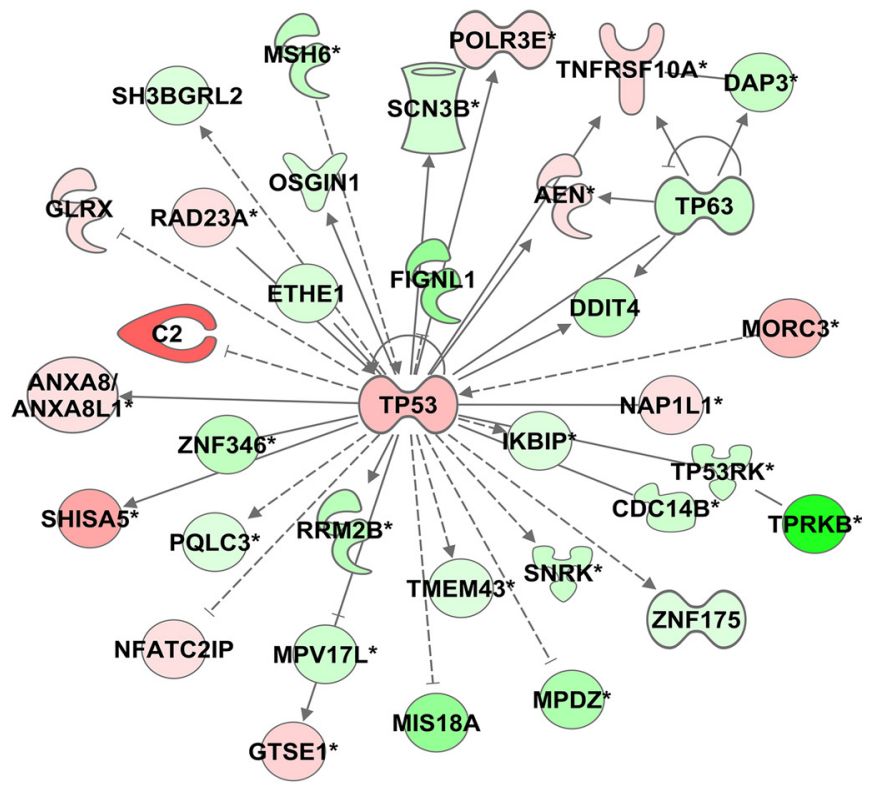

Figure 3. Top three networks of significantly associated molecules in TGF- $\beta 1+$ LPS + IFN $\gamma$-treated astrocytes. $A-C$, Schematic diagrams of the top three predesignated Associated Molecular Networks identified using Ingenuity Pathway Analysis software (IPA; Ingenuity) as being affected by TGF- $\beta 1+$ LPS + IFN $\gamma$ treatment of astrocytes. As defined in Table 3, the top three networks are Antigen Presentation and Cell Death ( $\boldsymbol{A}$ ); Cell Morphology, Cellular Compromise, and DNA Replication, Recombination, and Repair ( $\boldsymbol{B}$ ); and Genetic Disorder and Neurological Disease ( $\boldsymbol{C}$. Molecules are indicated by standard abbreviations. Molecular categories are indicated by icons defined in the icon key. Relative changes in gene expression are depicted by gradated shades of color coding: red, up; green, down. Direct and indirect interactions between molecules are depicted by solid and dotted lines, respectively.

ited little or no regulation (Table 6). These evaluations illustrated that a large number chemokines and cytokines exhibited a very high degree of regulation, as well as many growth factors; extracellular matrix molecules; transmembrane receptors; inflammation-related enzymes that produce small effector molecules; and intracellular signaling molecules including transcription factors, connexins, amino acid transporters, ion channels, and other astrocyte-related molecules (Table 6). It is noteworthy that many of these genes (demarcated by asterisks) exhibited synergistic regulation by combinatorial treat- ment with TGF $\beta+\mathrm{LPS}+\mathrm{IFN} \gamma$ relative to individual treatments with either TGF- $\beta 1$ or LPS +IFN $\gamma$ alone.

\section{Regulation of genes encoding GPCRs and their ligands}

We next examined the effects of combinatorial treatment with TGF $\beta+$ LPS + IFN $\gamma$ and noted a high degree of upregulation or downregulation of many genes encoding molecules associated with calcium signaling, including the GPCRs Cxcr4 (Fig. 4C), Adra2a (Table 1), P2ry6 (Fig. 3A; Table 2), P2ry14 (Table 2), Adora1 (Table 2), Gpr23 and Gpr156 (Table 2), and G-protein 


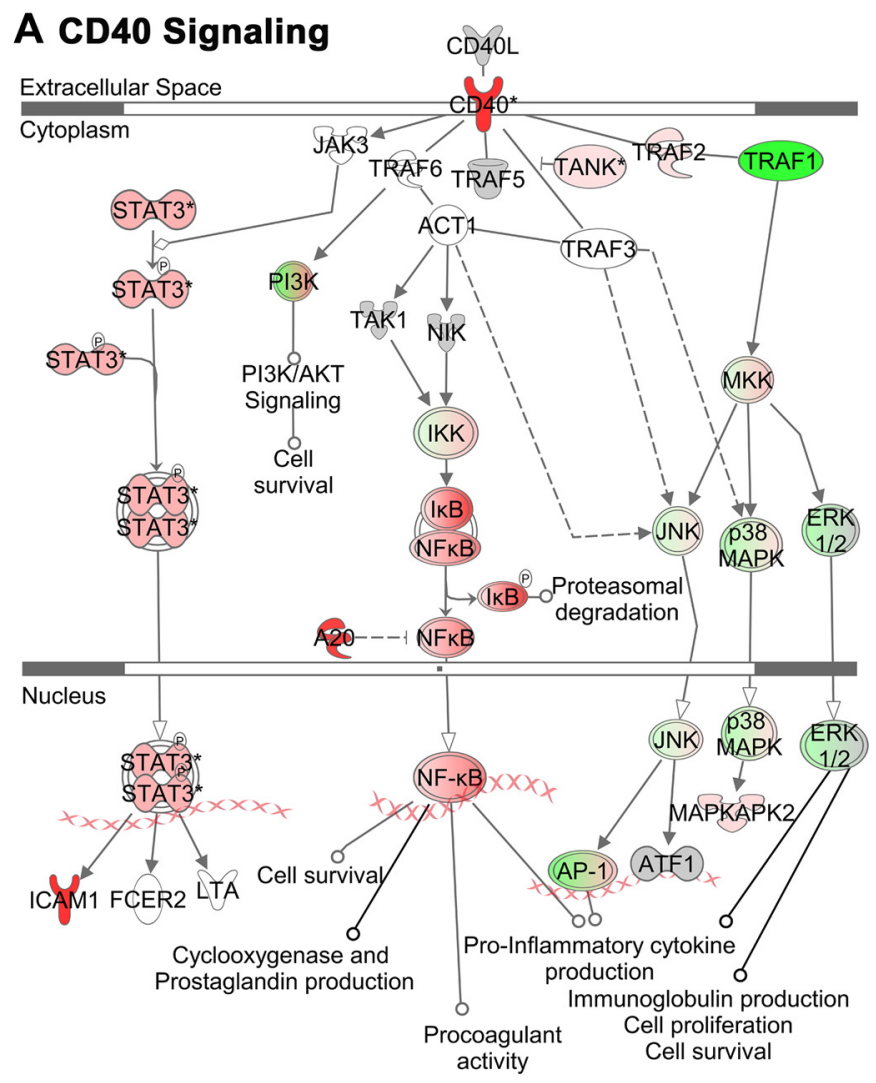

\section{Chemokine Signaling}

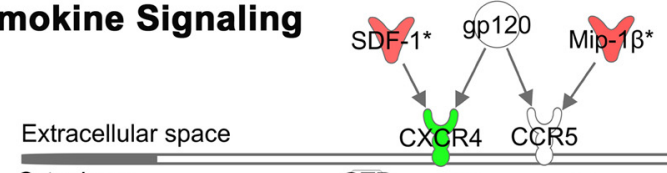

B IL-1 Signaling il-1
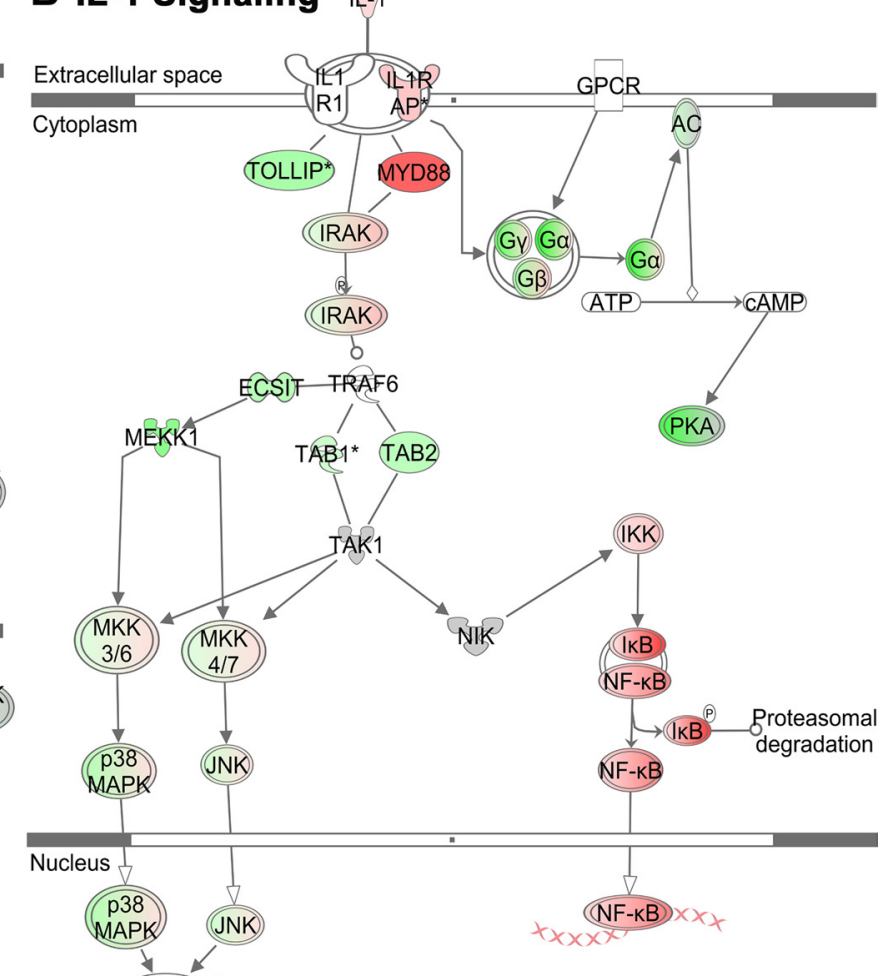

c-Junc-5os $x \times x+$

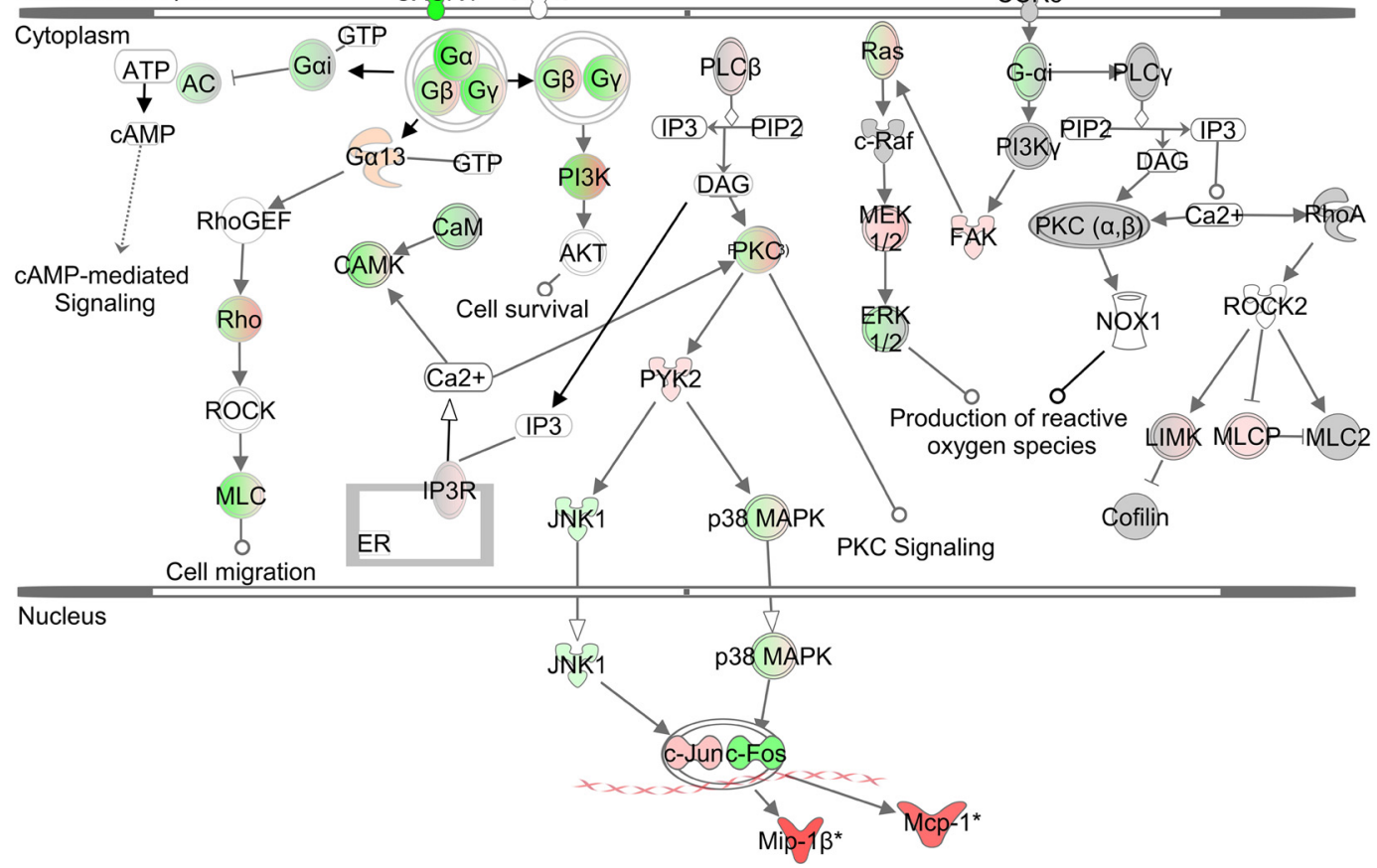

Figure 4. Three IPA Canonical Signaling Pathways: CD40, IL-1, and Chemokine Signaling in TGF- $\beta 1+$ LPS + IFN $\gamma$-treated astrocytes. $A-C$, Schematic diagrams of three of the top significantly altered predesignated Canonical Signaling identified using Ingenuity Pathway Analysis software (IPA; Ingenuity) as being affected by TGF- $\beta 1+$ LPS + IFN $\gamma$-treatment of astrocytes. As selected from Table 5, these pathways are CD40 Signaling ( $\boldsymbol{A})$, IL-1 Signaling $(\boldsymbol{B})$, and Chemokine Signaling $(\boldsymbol{C})$. Molecules are indicated by standard abbreviations. Relative changes in gene expression are depicted by gradated shades of color coding: red, up; green, down; white, no change or not applicable. Direct and indirect interactions between molecules are depicted by solid and dotted lines, respectively. 
Table 6. Individual genes

\begin{tabular}{|c|c|c|c|c|}
\hline Probe ID & Gene & TLG versus B & $\begin{array}{l}\text { LG versus B } \\
\log _{2} \text { ratio }\end{array}$ & $\begin{array}{l}\text { T versus } B \\
\log _{2} \text { ratio } \\
\end{array}$ \\
\hline \multicolumn{2}{|c|}{ Cytokines, chemokines } & \multicolumn{3}{|l|}{$\log _{2}$ ratio } \\
\hline 2777498 & $1 / 16$ & 2.40 & 1.84 & NS \\
\hline 1243601 & $116 *(b)$ & 3.84 & 2.03 & NS \\
\hline 2630852 & 117 & 1.18 & 1.18 & NS \\
\hline 1243862 & $1 / 11 *(b)$ & 4.30 & 0.67 & NS \\
\hline 2610234 & $\| 115$ & 2.79 & 2.96 & NS \\
\hline 2792502 & IL17d & -1.05 & -0.66 & -0.62 \\
\hline 2711461 & $\operatorname{Tgfb1}$ & 0.49 & NS & NS \\
\hline 2899863 & Inf & 1.29 & NS & NS \\
\hline 2690603 & Spp1 & 2.94 & NS & 1.30 \\
\hline 1245710 & C 12 (Mcp1) & 6.48 & 6.23 & NS \\
\hline 1231814 & $\mathrm{CAl}$ & 7.25 & 7.40 & NS \\
\hline 2835117 & $\mathrm{Cd} 7$ & 7.26 & 6.89 & NS \\
\hline 1238886 & $C c 18 *(b)$ & 2.51 & 1.83 & NS \\
\hline 2771766 & $(c / 12 *(b)$ & 2.53 & 1.60 & NS \\
\hline 2717015 & $C d 117^{*}(d)$ & 0.84 & NS & NS \\
\hline 1238886 & $\mathrm{Ccl} 8$ & 2.51 & 1.83 & NS \\
\hline 2763245 & Cxcl1 & 7.77 & 7.77 & NS \\
\hline 1215862 & $\mathrm{Cx} / 9$ & 7.77 & 7.84 & NS \\
\hline 3142803 & Cxcl10 & 7.34 & 7.39 & 0.50 \\
\hline 2658908 & Cxcl12(SDF-1) & 2.69 & 3.05 & NS \\
\hline 2687586 & Cxcl16 & 4.47 & 3.82 & NS \\
\hline \multicolumn{5}{|c|}{ Growth factors and related } \\
\hline 3137287 & $\operatorname{Lif}^{*}(b)$ & 2.29 & 0.53 & NS \\
\hline 3105417 & Bdnf & 0.87 & -0.49 & 1.05 \\
\hline 2659994 & $G d n f *(d)$ & 0.99 & NS & NS \\
\hline 2701233 & Fgf1 & -1.84 & -1.87 & NS \\
\hline 1239151 & Fgf2 & 0.84 & 0.53 & NS \\
\hline 1225565 & $\operatorname{lgf1}{ }^{*}(c)$ & 0.92 & NS & 1.45 \\
\hline 2937596 & $\mathrm{Ngfb}$ & 0.81 & 0.35 & 0.51 \\
\hline 2618714 & $P d g f b{ }^{*}(d)$ & 2.28 & NS & NS \\
\hline 2989955 & $B m p 1 *(d)$ & 0.72 & NS & NS \\
\hline 2659151 & Thbs 1 * $(d)$ & 1.23 & NS & NS \\
\hline 2484527 & Vegfa & 0.41 & NS & NS \\
\hline \multicolumn{5}{|c|}{ Immune and inflammation-related receptors } \\
\hline 2829008 & Lifr & 0.25 & 0.26 & NS \\
\hline 3138904 & Ntrk2 (TrkB) & -0.80 & -0.66 & NS \\
\hline 2602711 & Tgfbr1 & -0.23 & -0.28 & NS \\
\hline 2760979 & Tgfbr2 & NS & 0.73 & -0.61 \\
\hline 2789239 & Tgfbr3 & -0.66 & -0.51 & -0.43 \\
\hline 2733733 & $T / r 2$ & 6.50 & 6.50 & NS \\
\hline 2697002 & $T / r 3$ & 2.48 & 2.53 & NS \\
\hline 2752966 & TIr4 & 0.47 & 0.60 & NS \\
\hline 2742075 & $C D 14 *(b)$ & 3.51 & 2.97 & NS \\
\hline 2740852 & F2r (Par1) & NS & -0.28 & NS \\
\hline 2513826 & Tnfrsf11b & 3.38 & 2.12 & 1.52 \\
\hline 1226099 & $\operatorname{Tnfsf13b*(b)}$ & 2.30 & 1.29 & NS \\
\hline 3115796 & CD40 & 6.07 & 5.60 & NS \\
\hline 2589865 & $\mathrm{CD} 28^{*}(\mathrm{c})$ & NS & NS & 0.47 \\
\hline \multicolumn{5}{|c|}{ Transcription factors and intracellular signaling molecules } \\
\hline 1245579 & Jak2 & 1.63 & 1.44 & NS \\
\hline 2655721 & Stat1 & 4.15 & 4.23 & NS \\
\hline 2657822 & Stat2 & 2.71 & 2.87 & NS \\
\hline 3096144 & Stat3 & 1.33 & 1.38 & NS \\
\hline 2618176 & Soc3 & 1.70 & 1.14 & 0.67 \\
\hline 2938893 & Smad3 & 1.30 & 1.41 & NS \\
\hline 2706631 & Smad4 & -0.59 & -0.55 & NS \\
\hline 2971767 & $\operatorname{MyD88*}(b)$ & 2.72 & 3.02 & NS \\
\hline 2937735 & Irak2 & 0.86 & NS & 0.98 \\
\hline 2592476 & Nfkb1 & 2.21 & 1.91 & NS \\
\hline 2714534 & Map2k1 & 1.07 & 0.71 & NS \\
\hline 1245924 & Map3k8 & 2.73 & 2.63 & NS \\
\hline 2599782 & Irf1 & 4.82 & 5.09 & -0.35 \\
\hline 2664319 & Irf3 & -0.21 & NS & $\begin{array}{c}\text { NS } \\
\text { (Table continues.) }\end{array}$ \\
\hline
\end{tabular}

Table 6. Continued

\begin{tabular}{|c|c|c|c|c|}
\hline Probe ID & Gene & TLG versus $B$ & $\begin{array}{l}\text { LG versus } B \\
\log _{2} \text { ratio }\end{array}$ & $\begin{array}{l}\text { T versus } B \\
\log _{2} \text { ratio }\end{array}$ \\
\hline 2621752 & $\operatorname{lif5}{ }^{*}(b)$ & 2.04 & 1.66 & NS \\
\hline 2652857 & Ifi47 & 6.37 & 6.37 & NS \\
\hline 2604029 & $K I f 2^{*}(b)$ & 0.57 & 1.53 & NS \\
\hline 1252078 & Foxp $1 *(d)$ & 0.31 & NS & NS \\
\hline \multicolumn{5}{|c|}{ Extracellular matrix and cell-cell contact related } \\
\hline 2699488 & Lamb2 & -0.71 & -0.72 & NS \\
\hline 2974798 & Lamc1 & 0.95 & 1.08 & NS \\
\hline 2775307 & Lamc2 & 1.12 & 0.74 & NS \\
\hline 2670486 & Bcan & -1.04 & -0.59 & NS \\
\hline 2993652 & Ncan & NS & -0.63 & NS \\
\hline 1254975 & Has2 & 1.67 & 1.31 & NS \\
\hline 2864172 & Chst3 & 0.67 & NS & 0.47 \\
\hline 1216374 & Chst7 & 0.92 & 0.97 & NS \\
\hline 2643049 & Chst8 & -0.80 & -1.34 & 1.14 \\
\hline 1215528 & Chst11 & 1.56 & 0.49 & 0.83 \\
\hline 2862538 & Col12a1 & 1.19 & NS & NS \\
\hline 2599692 & Colm (Gliomedin)*(a) & 1.54 & 0.31 & 0.41 \\
\hline 2697380 & $\operatorname{Notch} 3 *(a)$ & 0.49 & -0.35 & 1.36 \\
\hline 2753809 & Mmp3 & 2.74 & 1.85 & NS \\
\hline 1215120 & $\operatorname{Sema} 4 A *(b)$ & 1.72 & 0.33 & NS \\
\hline 2790357 & Sema7a* $(c)$ & 0.47 & NS & 1.07 \\
\hline 2670172 & $\operatorname{ltg} a 5^{*}(d)$ & 0.77 & NS & NS \\
\hline \multicolumn{5}{|c|}{ Inflammatory-related enzymes } \\
\hline $1223499^{\circ}$ & $\operatorname{Nos} 2{ }^{*}(b)$ & 2.53 & 1.28 & NS \\
\hline 2650280 & Sod2 & 1.42 & 1.57 & NS \\
\hline 1241892 & Sod3 & 1.06 & 0.66 & NS \\
\hline 2786442 & Ptges & 1.60 & 1.97 & NS \\
\hline 2997494 & $\operatorname{Lox}{ }^{*}(c)$ & 2.42 & NS & 1.32 \\
\hline \multicolumn{5}{|c|}{ Channels and connexins } \\
\hline 2980661 & Aqp1 & 0.21 & NS & NS \\
\hline 2757232 & Aqp4 & NS & NS & NS \\
\hline 1214634 & Aqp9*(d) & -0.65 & NS & NS \\
\hline 1225901 & Aqp11 & -0.73 & -0.67 & -0.45 \\
\hline 1244291 & Gja1 (Cx43) & -0.97 & -1.11 & NS \\
\hline 2691641 & Gja5 $(C x 40) *(b)$ & 0.64 & 0.27 & NS \\
\hline 2999627 & $G j b 2(C \times 26) *(b)$ & 2.91 & 1.32 & NS \\
\hline 2946088 & Panx1 & 0.76 & 0.46 & NS \\
\hline 2621548 & $\operatorname{TrpA1}$ & NS & NS & NS \\
\hline \multicolumn{5}{|l|}{ Transporters } \\
\hline 3123195 & SIc1a2 (GIt1) & NS & 0.61 & NS \\
\hline 2905589 & Slc6a1 (Gat1) & -0.26 & -0.26 & NS \\
\hline 1212645 & Slc6a13 (Gat3) & NS & NS & NS \\
\hline 2948143 & Slc7a11 (xCT) & 2.49 & 2.98 & NS \\
\hline \multicolumn{5}{|c|}{ Astrocyte-related molecules } \\
\hline 2706906 & Fthfd (Aldh1/1) & -0.65 & -0.39 & NS \\
\hline 2644496 & Glul (GIn Synthetase) & -0.97 & -0.70 & NS \\
\hline 1214715 & Gfap & NS & NS & NS \\
\hline 2634742 & S100b & NS & NS & NS \\
\hline 2840213 & Cryab & NS & NS & NS \\
\hline 2712075 & Lcn2 (lipocalin2) & 4.98 & 4.98 & 0.82 \\
\hline 2697304 & Eln (elastin) *(c) & 1.81 & NS & 0.95 \\
\hline
\end{tabular}

NS, nonsignificant by criteria of FDR $>0.05$ or not within $0.20 \log _{2}$ change cutoff. * , Synergistic interaction of TLG treatment and $(a-d)=$ category of type of synergistic interaction as described in Table 2.

subunits, $\mathrm{G} \alpha, \beta, \gamma$ (Fig. $4 B, C$ ). Moreover, in certain cases there were multiple differentially expressed genes at all three signaling levels (extracellular trigger, transmembrane receptor, and intracellular effector), for example, the chemokine signaling pathway of ligand SDF- $1 \alpha / C x c l 12$, receptor Cxcr4, and intracellular effectors $(\mathrm{G} \alpha, \beta, \gamma)$, as shown in Figure $4 C$. These observations suggested the potential for inflammatory stimuli to substantially modulate astrocyte calcium signaling. We found these changes of particular interest because astrocytes display GPCR-mediated 


\section{A Microarray - GPCR Analysis TGF 12 \\ LG $51 \quad 16$ \\ TLG 4523

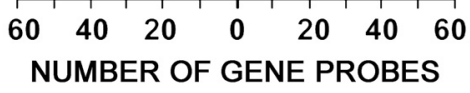

B qRT-PCR of GPCRs - TLG

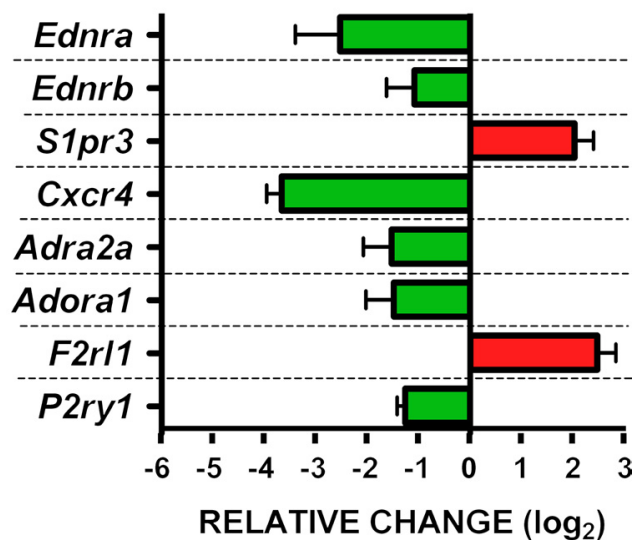

Figure 5. Genome-wide analysis of differentially expressed genes encoding GPCRs and qRTPCR validation. $\boldsymbol{A}$, All genes designated to encode GPCRs according to the IUPHAR database were cross-referenced with our microarray dataset (Fig. 1, $n=4$ from Fig. 1) and total number of gene probes showing differential expression after treatment of astrocytes with $T$, LG, or TLG versus $B$ was calculated. * A significant skew in genes differentially expressed, down versus up ( $p \leq 0.05$ Fisher's exact test). B, basal; T, TGF- $\beta 1$; LG, LPS + IFN $\gamma$; TLG, TGF- $\beta 1+$ LPS + IFN $\gamma$. $B, q R T-P C R$ validation of a cross section of differentially expressed genes encoding GPCRs in astrocytes exposed to TLG. Data are expressed as mean fold change $\left(\log _{2}\right)$ relative to basal + SEM ( $n=3$ from 3 independently generated samples from those used for gene arrays).

$\left[\mathrm{Ca}^{2+}\right]_{i}$ increases that are under extensive investigation as potential means of mediating various dynamic astrocyte functions (Verkhratsky et al., 1998; Attwell et al., 2010; Halassa and Haydon, 2010). We therefore performed a systematic analysis of all genes encoding known GPCRs [i.e., those annotated on the International Union of Basic and Clinical Pharmacology (IUPHAR) database] (Sharman et al., 2011) to look for highly regulated genes among GPCRs, and G-protein effectors. This analysis revealed a large number of significantly regulated genes (Fig. 5A), and also indicated a bias toward downregulation among those genes that were significantly modulated, as reflected in the significantly greater number of genes that were downregulated versus upregulated (assessed via Fisher's exact test, $p \leq 0.05$; Fig. 5A), as well as in the magnitude of the changes among individual genes (Tables 7,8 ). To validate the changes revealed by genomic microarray profiling, we performed qRT-PCR and found similar changes in mRNA expression of selected GPCR genes, Cxcr4, Adra2a, Ednra, Ednrb, P2ry1, Adora1, S1pr3, and F2rl1 (Fig. 5B). Canonical Pathway (Ingenuity) analysis further revealed that, as in the case of CXCR4 (Fig. 4C), various other pathways exhibited highly regulated genes at the levels of both receptor and intracellular effectors, including the type $2_{\mathrm{A}}$ $\alpha$-adrenergic receptor (Fig. $6 A$ ), endothelin receptors type A and $\mathrm{B}$ (Fig. 6B), and various $\mathrm{P} 2 \mathrm{Y}$ receptors (Fig. 6C). These findings pointed toward the potential for diverse effects of inflammatory
Table 7. Top upregulated and downregulated GPCRs by TGF- $\beta 1+L P S+I F N \gamma$

\begin{tabular}{|c|c|c|}
\hline Gene & Gene description & $\begin{array}{l}\log _{2} \\
\text { Ratio }\end{array}$ \\
\hline \multicolumn{3}{|c|}{ Top 15 upregulated GPCRs } \\
\hline P2ry6 & Purinergic receptor P2Y, G-protein coupled 6 & 2.11 \\
\hline S1pr3 & $\begin{array}{l}\text { Endothelial differentiation, sphingolipid } \\
\text { GPCR } 3\end{array}$ & 1.13 \\
\hline Gpr158 & GPCR 158 & 1.04 \\
\hline Gpr83 & GPCR 83 & 1.01 \\
\hline $\mathrm{C}(\mathrm{Cr} / 2$ & Chemokine (C-C motif) receptor-like 2 & 0.85 \\
\hline Fzd1 & Frizzled homolog 1 (Drosophila) & 0.83 \\
\hline P2ry14 & Purinergic receptor P2Y, G-protein coupled 14 & 0.78 \\
\hline Gpr123 & GPCR & 0.73 \\
\hline Gpr172b & GPCR172B & 0.58 \\
\hline Gpr108 & GPCR 108 & 0.42 \\
\hline Vipr1 & Vasoactive intestinal peptide receptor 1 & 0.35 \\
\hline Niacr1 & GPCR 109A/niacin receptor 1 & 0.34 \\
\hline F2rl1 & Coagulation factor II (thrombin) receptor-like 1 & 0.30 \\
\hline Opn3 & Opsin 3 & 0.27 \\
\hline Gpr64 & GPCR 64 & 0.27 \\
\hline \multicolumn{3}{|c|}{ Top 15 downregulated GPCRs } \\
\hline Adra2a & $\alpha$-2A-adrenergic receptor & -2.55 \\
\hline Cxcr4 & Chemokine (C-X-C motif) receptor 4 & -1.85 \\
\hline Ednrb & Endothelin receptor type B & -1.67 \\
\hline Gpr146 & GPCR 146, transcript variant 2 & -1.57 \\
\hline Fzd 2 & Frizzled homolog 2 (Drosophila) & -1.31 \\
\hline P2ry1 & Purinergic receptor P2Y, G-protein coupled 1 & -1.29 \\
\hline Ednra & Endothelin receptor type A & -1.17 \\
\hline Gpr19 & GPCR 19 & -1.16 \\
\hline Lpar4 & GPCR 23 & -1.15 \\
\hline Gpr30 & GPCR 30 & -1.06 \\
\hline Gpr12 & GPCR 12 & -1.00 \\
\hline Gpr85 & GPCR 85 & -0.94 \\
\hline Celsr2 & Cadherin, EGF LAG seven-pass G-type receptor 2 & -0.93 \\
\hline Gprc5b & GPCR, family $C$, group 5 , member B & -0.92 \\
\hline Adora1 & Adenosine $A 1$ receptor & -0.87 \\
\hline
\end{tabular}

Table 8. Top upregulated and downregulated GPCR effectors by TGF- $\beta 1+$ LPS +IFN $\gamma$

\begin{tabular}{llr}
\hline Gene & Gene description & $\begin{array}{c}\log _{2} \\
\text { ratio }\end{array}$ \\
\hline $\begin{array}{l}\text { Top 5 upregulated G-proteins } \\
\text { Gnb4 }\end{array}$ & Guanine nucleotide binding protein (Gnbp; & 0.91 \\
& $\quad$ G-protein), $\beta 4$ \\
Gnl1 & Gnbp (G-protein)-like 1 (Gna-rs1) & 0.60 \\
Gng2 & Gnbp (G-protein), $\gamma 2$ transcript variant 1 & 0.55 \\
Gna13 & Gnbp (G-protein), $\alpha$ 13 & 0.40 \\
Gnb211 & Gnbp (G-protein), $\beta$ polypeptide 2 like 1 (Gnb2-rs1) & 0.33 \\
Top 5 downregulated G-proteins & \\
Gna01 & Gnbp (G-protein), $\alpha$ 0 transcript variant A & -1.68 \\
Gng7 & Gnbp (G-protein), $\gamma 7$ subunit transcript variant 2 & -1.29 \\
Gna14 & Gnbp (G-protein), $\alpha$ 14 & -1.12 \\
Gnb5 & Gnbp (G-protein), $\beta$ 5 transcript variant 2 & -0.75 \\
Gnai2 & Gnbp (G-protein), $\alpha$ inhibiting 2 & -0.58 \\
\hline
\end{tabular}

stimuli on different forms of ligand-evoked astrocyte calcium signaling. We also noted that certain other GPCRs implicated in astrocyte calcium signaling were not significantly regulated by the inflammatory stimuli used in this study, including various metabotropic glutamate receptors (mGluR) subunits, mGlur (probe \#s Grm1, ILMN_2665238; Grm3, ILMN_1238513; Grm4, ILMN_3162152; Grm6, ILMN_3162125; Grm7, ILMN_2872782; and Grm8, ILMN_ 2711523). 


\section{A $\alpha$-Adrenergic Signaling}

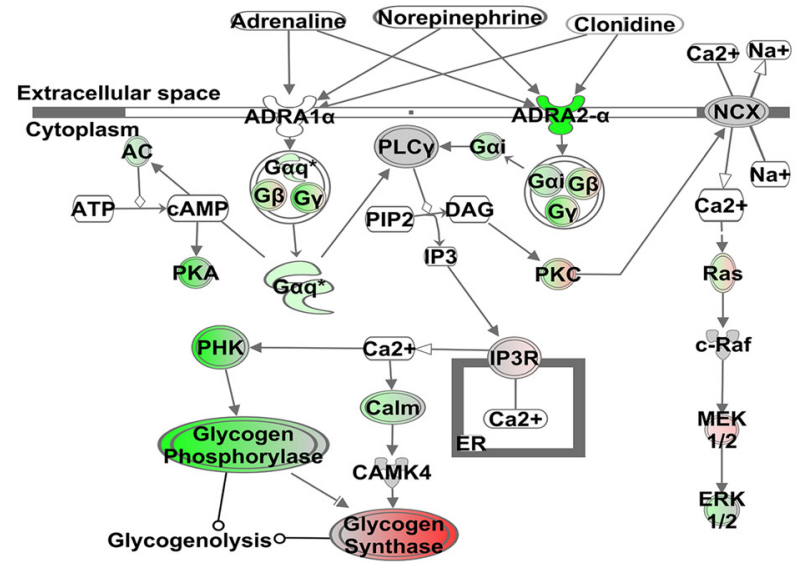

\section{B Endothelin-1 Signaling}

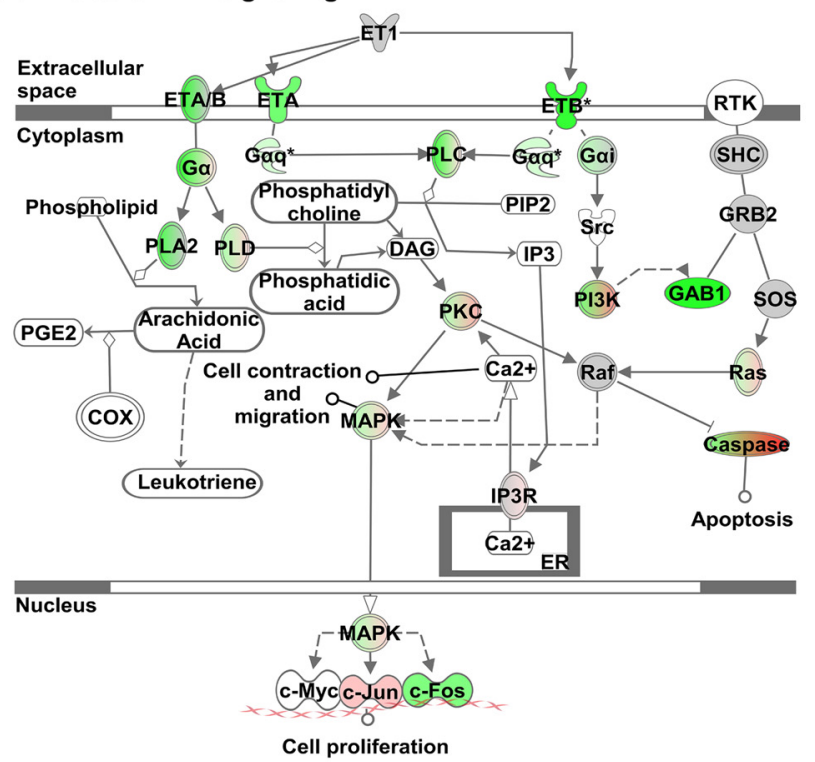

\section{CP2Y Signaling}

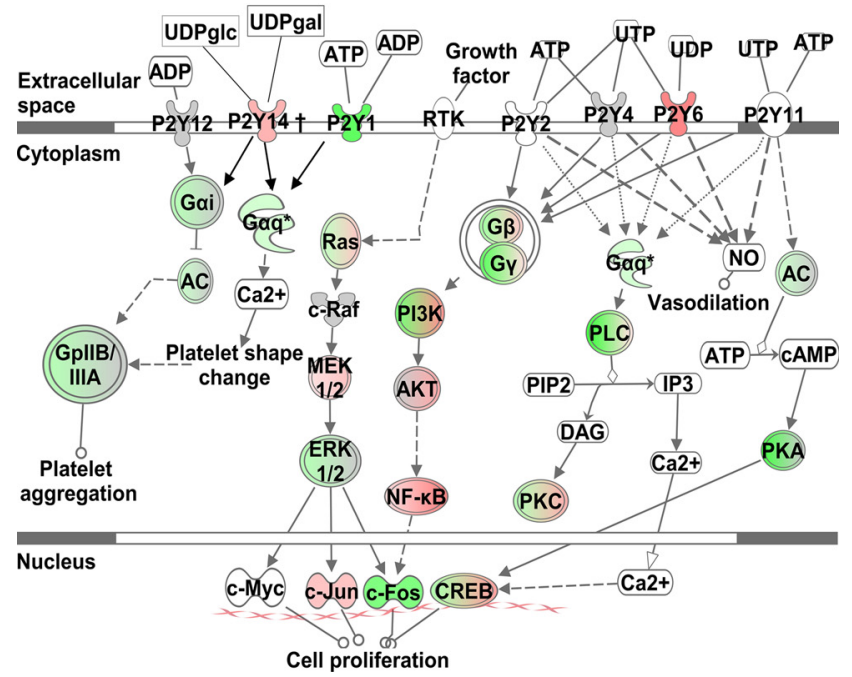

Figure 6. GPCR Canonical Signaling Pathways. A-C, Schematic diagrams of three significantly altered GPCR Canonical Signaling Pathways identified using Ingenuity Pathway Analysis software (IPA; Ingenuity) as being affected by TGF- $\beta 1+\mathrm{LPS}+$ IFN $\gamma$-treatment of astrocytes. As selected from Table 7, these pathways are $\alpha$-Adrenergic Signaling $(\boldsymbol{A})$, Endothelin-1 Signaling $(\boldsymbol{B})$, and P2Y Signaling ( $\boldsymbol{C}$. Molecules are indicated by standard abbreviations. Relative

\section{Effects of TGF $\beta+$ LPS + IFN $\gamma$ on astrocyte GPCR-evoked} calcium signaling

Given that stimulation with combinatorial inflammatory mediators substantially altered the gene expression of many GPCRs and G-protein effectors in astrocytes, we next evaluated the effects of treatment with TGF $\beta+$ LPS + IFN $\gamma$ on GPCRmediated astrocyte calcium signaling. We examined GPCRs whose expression levels had been significantly modulated down or up by TGF $\beta+$ LPS + IFN $\gamma$ treatment (Table 7), and focused on a cross section of GPCRs activated by different molecular classes of ligands, including cytokines, growth factors, catecholamines, and purine nucleotides.

Before examining GPCR regulated changes in $\left[\mathrm{Ca}^{2+}\right]_{i}$, we asked whether treatment with TGF $\beta+\mathrm{LPS}+\mathrm{IFN} \gamma$ altered the resting $\left[\mathrm{Ca}^{2+}\right]_{i}$ in astrocytes. Findings from Fura2 bulk-loaded astrocytes indicated that resting $\left[\mathrm{Ca}^{2+}\right]_{i}$ levels did not differ significantly $(p>0.05$, un-paired $t$ test) between untreated and TGF $\beta+$ LPS + IFN $\gamma$-treated astrocytes, with values approximating $90 \mathrm{nM}$ in both cases (basal, $84 \pm 6 \mathrm{nM}$; TGF $\beta+\mathrm{LPS}+\mathrm{IFN} \gamma$, $89 \pm 4 \mathrm{nM}$, mean \pm SEM; $n=84-98$ from 5 to 6 separate experiments), a value similar to that reported previously (Shigetomi et al., 2012). This result is consistent with our microarray data showing that expression of the $\operatorname{Trp} A 1$ ion channel, a contributor to astrocyte resting calcium levels (Shigetomi et al., 2012), is not altered by treatment with TGF $\beta+\mathrm{LPS}+\operatorname{IFN} \gamma$ compared with basal (Table 6). These resting calcium measurements also indicate that astrocyte cell membranes were intact. Second we examined whether spontaneous (nonevoked) increases in $\left[\mathrm{Ca}^{2+}\right]_{i}$ varied between basal and TGF $\beta+\mathrm{LPS}+\mathrm{IFN} \gamma$-treated astrocytes. Interestingly, we found that TGF $\beta+\mathrm{LPS}+$ IFN $\gamma$-treated cells had fewer spontaneous events over time (basal, $0.09 \pm 0.02$ events/ min; TGF $\beta+$ LPS + IFN $\gamma, 0.03 \pm 0.01$ events $/$ min, mean \pm SEM, $p \leq 0.05$ assessed via unpaired $t$ test; $n=84-111$ from 5 to 6 experiments), but the peak amplitude of these spontaneous events did not differ significantly from one another (basal, $0.22 \pm$ 0.05 ; TGF $\beta+$ LPS + IFN $\gamma, 0.41 \pm 0.18$ mean \pm SEM; $p>0.05$ as assessed via Mann-Whitney test).

We next determined whether GPCR ligand-evoked increases in astrocyte $\left[\mathrm{Ca}^{2+}\right]_{i}$ differed among TGF $\beta+\mathrm{LPS}+\mathrm{IFN} \gamma$-treated astrocytes compared with basal. We first examined representative receptors whose gene expression levels had declined after TGF $\beta+$ LPS + IFN $\gamma$ treatment, Cxcr4, Adra2a, Ednrb, Adora, and P2ryl (Table 7; Fig. 5). Stimulation of astrocytes with various selective agonists for these receptors increased $\left[\mathrm{Ca}^{2+}\right]_{i}$ in control astrocytes, including CXCL12/SDF-1 $\alpha$, the endogenous and selective agonist of chemokine receptor CXCR4; guanfacine $\mathrm{HCl}$, an ADRA2A-selective agonist; IRL1620, an endothelin receptor type B (EDRNB)-selective agonist; CCPA, an ADORA1-selective agonist; and ADP $\beta$ S, a P2Y1-selective agonist (Fig. 7). For each of these agonists, TGF $\beta+\mathrm{LPS}+\mathrm{IFN} \gamma$-treated astrocytes exhibited a significantly diminished increase in $\left[\mathrm{Ca}^{2+}\right]_{i}$ levels compared with untreated (basal) astrocytes (Fig. 7). For four of these agonists, SDF- $1 \alpha$, guanfacine HCl, CCPA, and IRL1620, the TGF $\beta+$ LPS + IFN $\gamma$-induced diminution in $\left[\mathrm{Ca}^{2+}\right]_{i}$ elevations was due at least in part to a significant reduction in the number of astrocytes that responded, whereas for ADP $\beta S$, all cells continued to respond (Fig. 7). In addition, application of another adrenergic

changes in gene expression are depicted by gradated shades of color coding: red, up; green down; white, no change. Direct and indirect interactions between molecules are depicted by solid and dotted lines, respectively. 


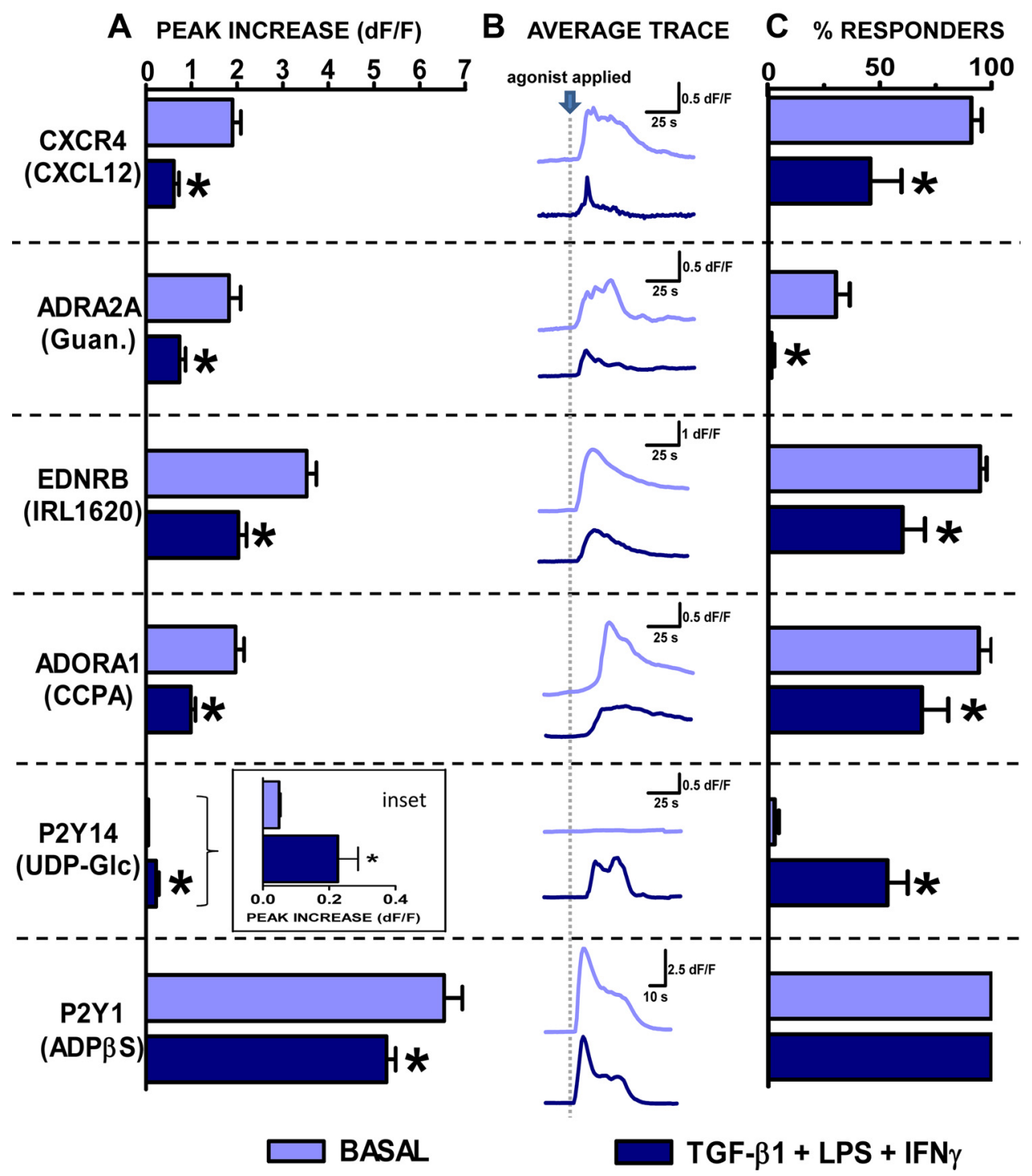

Figure 7. Calcium responses elicited by selective GPCR agonists in untreated and TGF- $\beta 1+$ LPS + IFN $\gamma$-treated astrocytes. Untreated and TGF- $\beta 1+$ LPS + IFN $\gamma$ (TLG)-treated astrocytes were bulk loaded with the calcium indicator dye Fluo-4 and imaged before, during (30 s), and after application of agonists selective for specific GPCRs as indicated: left, CXCL12, $30 \mathrm{ng} / \mathrm{ml}$; guanfacine HCI (Guan.), $10 \mu \mathrm{m}$; IRL1620, $100 \mathrm{nm;} \mathrm{CCPA,} 100 \mathrm{~nm}$; UDP-Glc, $100 \mu \mathrm{m}$; and ADP $\beta S, 10 \mu \mathrm{m}$. Data are represented as $(\boldsymbol{A})$ mean peak increase in intracellular calcium levels ([Ca $\left.\left.{ }^{2+}\right]_{j}\right)(\mathrm{dF} / F)+$ SEM, $(\boldsymbol{B})$ average trace depicting $\left[\mathrm{Ca}^{2+}\right]_{i}(d F / F)$ over time $(s)$, and $(\boldsymbol{C})$ mean percentage cells responding + SEM. Significance $(p \leq 0.05)$ was assessed via $(\boldsymbol{A})$ Mann-Whitney test or $(\boldsymbol{C})$ unpaired $t$ test following normalization of data. ${ }^{*}$, Indicates significantly different from untreated (basal) control. (CXCL12, $n=86-107$ cells from 3 experiments; guanfacine $\mathrm{HCl}, n=78-93$ from 4 experiments; IRL1620, $n=115-146$ from 3-5 experiments; (CPA, $n=83-89$ from 4 experiments; UDP-Glc, $n=44-47$ from 3 experiments; ADP $\beta S, n=67-94$ from 3 experiments.)

ADRA2-selective agonist, B-HT 933, to Fluo-4-loaded astrocytes revealed a similar functional response to that of the ADRA2Aselective agonist guanfacine with the peak increase in $\left[\mathrm{Ca}^{2+}\right]_{i}$ in TGF $\beta+$ LPS + IFN $\gamma$-treated astrocytes significantly attenuated compared with that of basal (basal, $0.9 \pm 0.1 d F / F$; TGF $\beta+$ LPS + IFN $\gamma 0.2 \pm 0.1$, mean peak increase in $\left[\mathrm{Ca}^{2+}\right]_{i} \pm \mathrm{SEM} ; n=$ 85-92 from 3 to 4 experiments; $p \leq 0.05$ as assessed via MannWhitney test). Additionally, a different EDRNB-selective agonist BQ-3020 was found to mirror that of IRL1620 with the peak increase in $\left[\mathrm{Ca}^{2+}\right]_{i}$ significantly attenuated in TGF $\beta+\mathrm{LPS}+$ IFN $\gamma$-treated versus basal astrocytes (basal, $4.1 \pm 0.2 \mathrm{dF} / \mathrm{F}$; $\mathrm{TGF} \beta+\mathrm{LPS}+\mathrm{IFN} \gamma, 1.8 \pm 0.2 d F / F$ mean peak increase in $\left[\mathrm{Ca}^{2+}\right]_{i}, \pm$ SEM; $n=58-111$ from three experiments $p \leq 0.05$ as assessed via Mann-Whitney test). We then examined a receptor whose gene expression levels had increased after TGF $\beta+$ LPS + IFN $\gamma$ treatment, P2ry14 (Table 7). To stimulate P2Y14, we used the receptor-selective and endogenous ligand, UDP-glucose (Ab- bracchio et al., 2003). Interestingly, in basal astrocytes, UDPglucose had no detectable effect on astrocyte $\left[\mathrm{Ca}^{2+}\right]_{i}$; however, in astrocytes treated with TGF $\beta+\mathrm{LPS}+\mathrm{IFN} \gamma$, UDP-glucose resulted in a significant increase in $\left[\mathrm{Ca}^{2+}\right]_{i}$, in $\sim 50 \%$ of the cells (Fig. 7). It is noteworthy that all of the decreases or increases in ligand-evoked $\left[\mathrm{Ca}^{2+}\right]_{i}$ responses that were induced by treatment of astrocytes with TGF $\beta+$ LPS + IFN $\gamma$ mirrored the relative up or down changes measured in gene expression of the respective receptors: Cxcr4, Adra2a, Ednrb, Adora1, P2ry14, and P2ry1 (Table 7; Fig. $5 B$ ).

In addition to testing GPCR-selective agonists as just described, we wished to determine whether endogenously produced GPCR agonists would yield similar results. To do so we tested the effects of epinephrine, which activates the adrenoceptor family of receptors; endothelin-1, which activates the endothelin family of receptors; adenosine, which activates the adenosine family of receptors; UDP-galactose, another P2Y14- 


\section{A PEAK INCREASE (dF/F) B AVERAge tRACE C \% RESPONDERS}

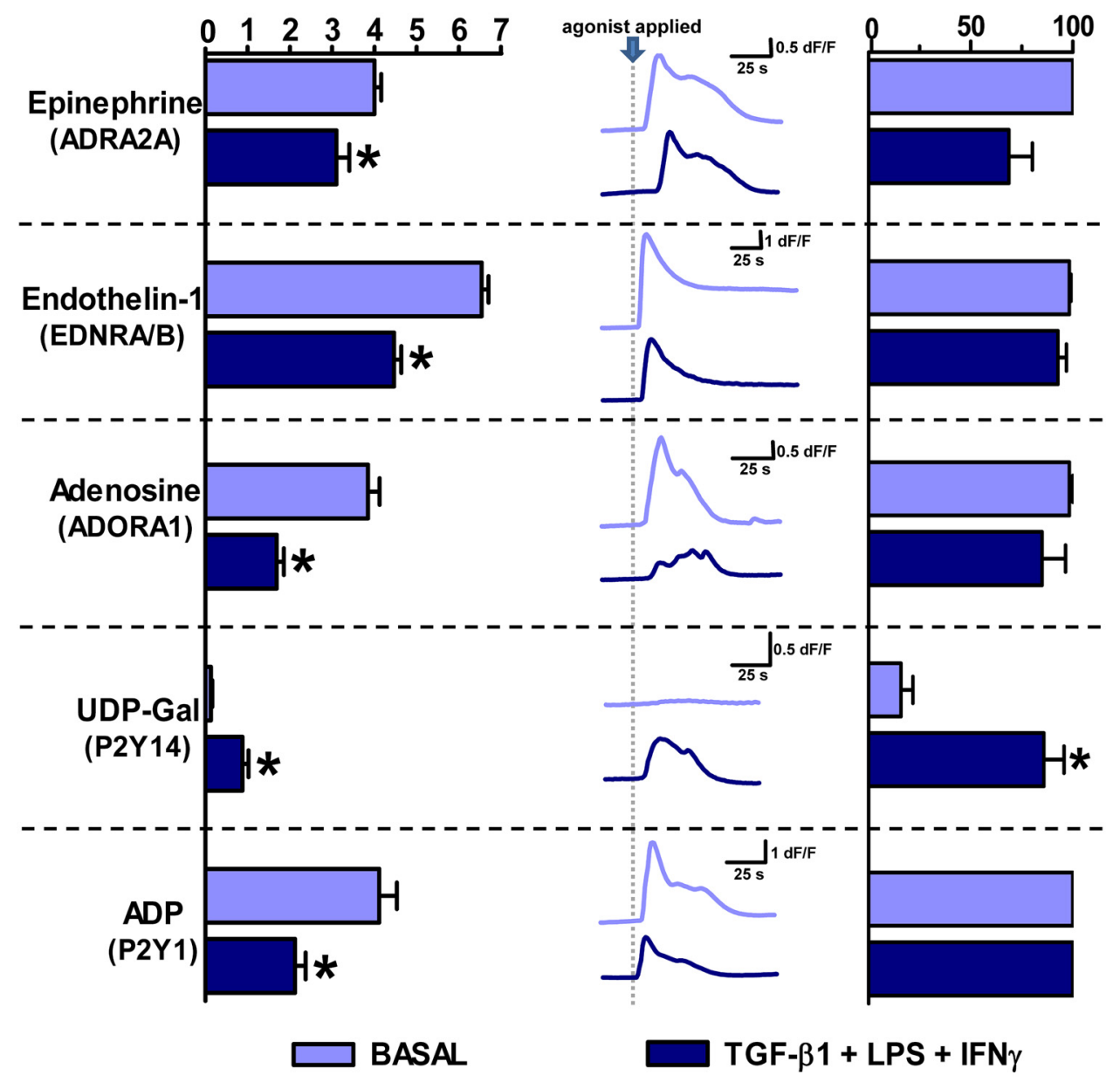

Figure 8. Calcium responses elicited by endogenous GPCR agonists in untreated and TGF- $\beta 1+$ LPS + IFN $\gamma$-treated astrocytes. Untreated and TGF- $\beta 1+\mathrm{LPS}+\mathrm{IFN} \gamma(\mathrm{TLG})$-treated astrocytes were bulk loaded with the calcium indicator dye Fluo-4 and imaged before, during (30s), and after application of agonists (epinephrine, $100 \mathrm{ng} / \mathrm{ml}$; endothelin-1, $100 \mathrm{~nm}$; adenosine, $1 \mu \mathrm{M}$; UDP-Gal, $300 \mu \mathrm{m} ; \mathrm{ADP}, 1 \mu \mathrm{M})$ as indicated (left column). Data are represented as $(\boldsymbol{A})$ mean peak increase in intracellular calcium levels $\left[\mathrm{Ca}^{2+}\right]_{i}(\mathrm{dF} / \mathrm{F})+\mathrm{SEM},(\boldsymbol{B})$ average trace depicting $\left[\mathrm{Ca}{ }^{2+}\right]_{i}(\mathrm{dF} / \mathrm{F})$ over time $(s)$, and $(\boldsymbol{C})$ Mean percentage cells responding + SEM. Significance $(p \leq 0.05)$ was assessed via $(\boldsymbol{A})$ Mann-Whitney test or $(\boldsymbol{C})$ unpaired $t$ test following normalization of data. ${ }^{*}$, Indicates significantly different from untreated (basal) control. (Epinephrine, $n=66-85$ cells from 3 experiments; endothelin- $1, n=130-133$ from 3 experiments; adenosine, $n=64$ from 3 experiments; UDP-Gal, $n=40-47$ from 3 experiments; ADP, $n=33-35$ from 3- 4 experiments.)

selective endogenous agonist; and $\mathrm{ADP}$, which activates the purinergic $\mathrm{P} 2 \mathrm{Y}$ family receptors. In each case, the endogenously produced ligands elicited approximately similar responses to those noted with the selective agonists, and the effect of TGF $\beta+$ LPS + IFN $\gamma$ treatment on ligand-evoked responses was essentially the same (compare Figs. 7 and 8). As expected, the response for ligands capable of activating more than one receptor led to a larger rise in $\left[\mathrm{Ca}^{2+}\right]_{i}$.

Last, we determined the effects of siRNA knockdown of several representative GPCRs on ligand-evoked increases in $\left[\mathrm{Ca}^{2+}\right]_{i}$. Basal or TGF $\beta+$ LPS + IFN $\gamma$-treated astrocytes were transfected with control siRNA or siRNA specific for the En$d r b, P 2 r y 1$, or P2ry 14 receptors. For P2ry1, selective siRNA resulted in a $43-50 \%$ reduction in the peak increases in $\left[\mathrm{Ca}^{2+}\right]_{i}$ compared with control siRNA (Fig. 9). For Ednrb and P2ry14, selective siRNA resulted in an $85-90 \%$ reduction in the peak increases in $\left[\mathrm{Ca}^{2+}\right]_{i}$ compared with control siRNA, essentially abolishing the responses (Fig. 9). To test whether the siRNA knockdown effect might be due to decrease in cell health or viability, stimulation with ATP was used. These tests showed that ATP responses remained intact despite a decrease in the specific receptor-evoked $\left[\mathrm{Ca}^{2+}\right]_{i}$ that was due to receptor-specific siRNA (compared with control siRNA). For example, in P2y14 siRNA-transfected astrocytes, ATP $(10 \mu \mathrm{M})$ elicited a peak increase in $\left[\mathrm{Ca}^{2+}\right]_{i}$ that was similar to that elicited in negative control siRNA-transfected astrocytes (control siRNA, $5.2 \pm 0.3 \mathrm{dF} / \mathrm{F} ;$ P2ry $14 \mathrm{siRNA}, 4.8 \pm 0.1 \mathrm{dF} / \mathrm{F}$, mean \pm SEM; $p>0.05$ as assessed via Mann-Whitney test; $n=63-107$ from 3 to 4 separate experiments). These observations indicated that the siRNA knockdown effects were receptor specific, and not due to a general inability of these cells to respond to agonists in evoking a rise in $\left[\mathrm{Ca}^{2+}\right]_{i}$.

Together, these siRNA findings confirmed that the observed changes in $\left[\mathrm{Ca}^{2+}\right]_{i}$ were mediated via the specific receptors studied.

\section{Effects of TGF $\beta+$ LPS +IFN $\gamma$ on astrocyte expression of} representative molecules in vivo

The findings presented thus far were derived from in vitro experiments using primary cultures of cortical astrocytes. We next sought to test the potential relevance in vivo of our observations. To do so, we examined the effects of our combinatorial inflammatory stimuli on expression by cortical astrocytes in vivo of 
A

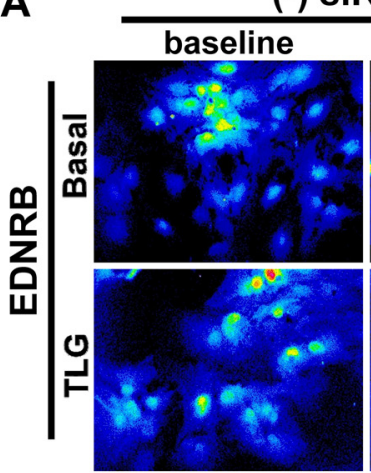

(-) SiRNA

B

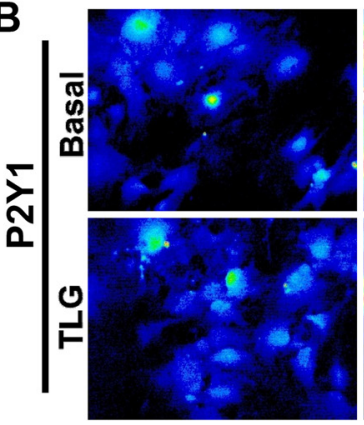

C

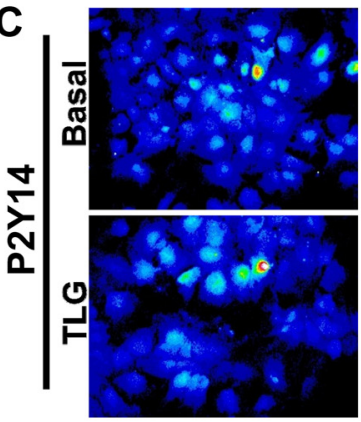

peak response
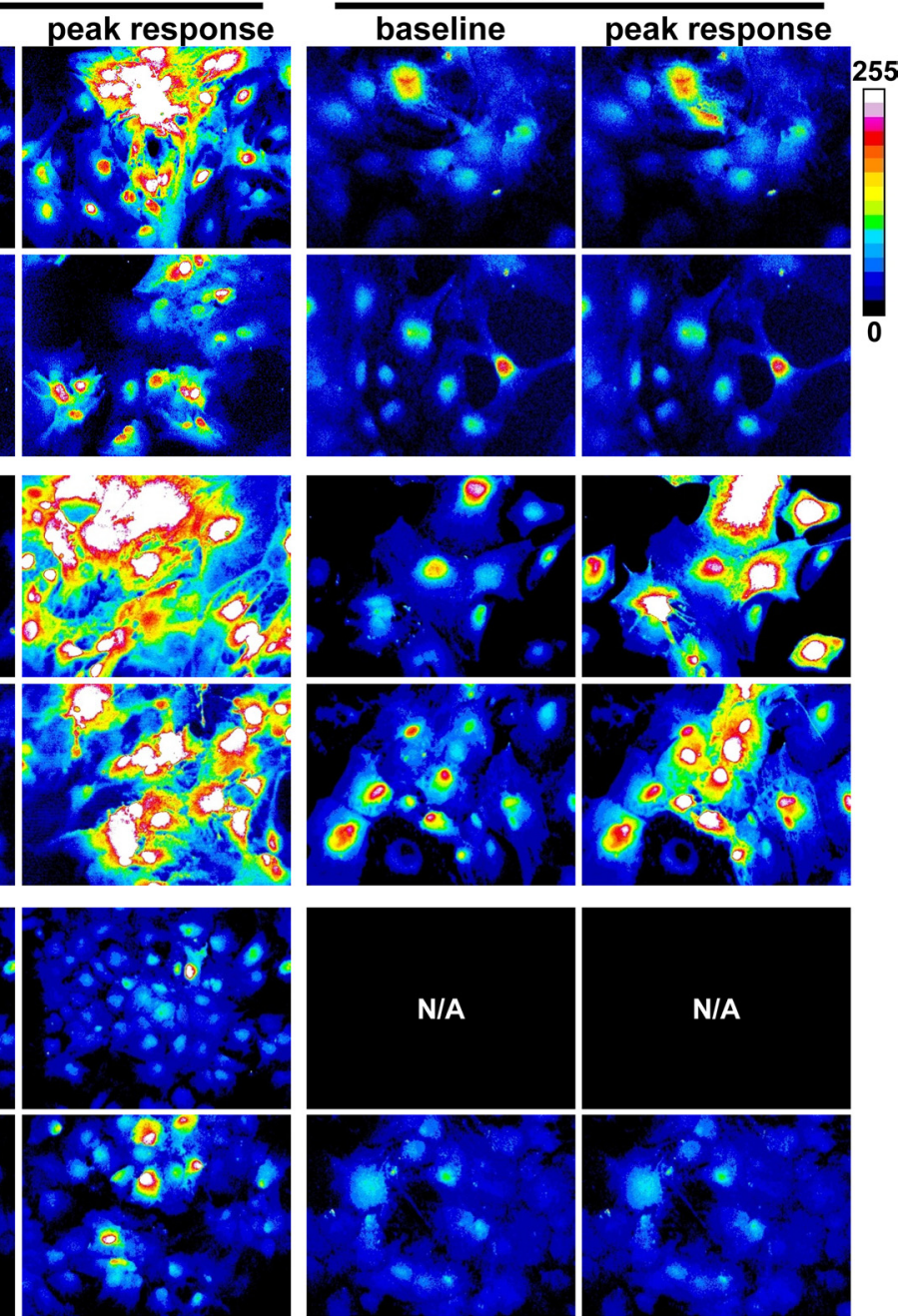

(+) SiRNA
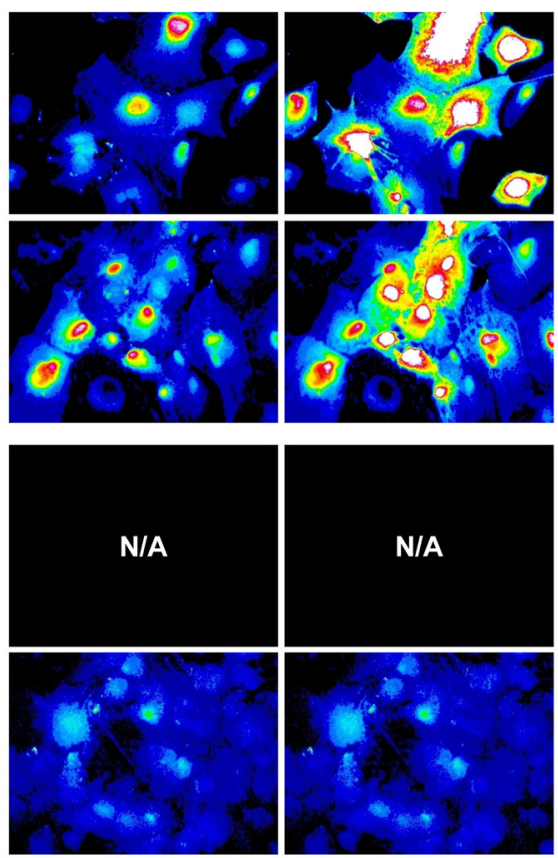

D

\begin{tabular}{|c|c|c|c|c|c|}
\hline SiRNA & $\begin{array}{l}\text { Receptor } \\
\text { Agonist }\end{array}$ & $\begin{array}{l}\text { Treatment } \\
\text { condition }\end{array}$ & $\begin{array}{c}\text { Control siRNA } \\
\text { (Mean dF/F } \pm \text { SEM) }\end{array}$ & $\begin{array}{l}\text { siRNA Gene KD } \\
\text { (Mean dF/F } \pm \text { SEM) }\end{array}$ & $\begin{array}{c}\% \mathrm{KD} \\
(\%)\end{array}$ \\
\hline \multirow{2}{*}{ EDNRB } & \multirow{2}{*}{ IRL1610 } & Basal & $3.06 \pm 0.13$ & $0.29 \pm 0.08 *$ & 90.5 \\
\hline & & TLG & $2.65 \pm 0.39$ & $0.38 \pm 0.08 *$ & 85.7 \\
\hline \multirow{2}{*}{ P2Y1 } & \multirow{2}{*}{ ADP $\beta S$} & Basal & $6.82 \pm 0.25$ & $3.38 \pm 0.41 *$ & 50.5 \\
\hline & & TLG & $5.49 \pm 0.42$ & $3.12 \pm 0.44 *$ & 43.2 \\
\hline \multirow{2}{*}{ P2Y14 } & \multirow{2}{*}{ UDP-glc } & Basal & N/A & N/A & N/A \\
\hline & & TLG & $0.72 \pm 0.14$ & $0.09 \pm 0.01 *$ & 87.3 \\
\hline
\end{tabular}

Figure 9. Representative images of peak responses to GPCR receptor-selective agonists with or without receptor-specific siRNA knockdown. Normal nontransfected [( -) siRNA], negative contro siRNA-transfected or Ednrb-, P2ry1-, or P2ry14-siRNA transfected [(+) siRNA] astrocytes were exposed to medium alone (basal) or TGF- $\beta 1+$ LPS + IFN $\gamma$ (TLG). From 22-30 hours following administration of control medium or that containing TLG, astrocytes were bulk loaded with the calcium indicator dye Fluo-4 and imaged before, during (30 s), and after application of receptorselective agonists: EDNRB (A), $100 \mathrm{~nm} \mathrm{IRL1620,} \mathrm{P2Y1} \mathrm{(B),} 10 \mu \mathrm{m} \mathrm{ADP} \beta S$, P2Y14 (C), and UDP-Glc, $300 \mu \mathrm{m}$. Shown are representative images for baseline and the peak increase in $\left[\mathrm{Ca}^{2+}\right]_{i}$ ( $d F$ intensity), as indicated, in response to the agonist application for both basal and TLG-treated cells with and without siRNA. Each image is representative of at least three experiments. Note: Given that UDP-GIc did not elicit a response in basal astrocytes, siRNA knockdown for P2y14 in basal astrocytes was not performed as indicated via N/A. D, Quantification of functional knockdown (KD) of agonist-triggered response (i.e., KD of measured increase in $\left.\left[\mathrm{Ca}^{2+}\right]_{i}\right)$ (from $\boldsymbol{A}-\boldsymbol{C}$ ). Results are presented as mean $d F / F \pm$ for each treatment condition and as percentage $\mathrm{KD}$. ${ }^{*}$, Indicates a significant KD compared with respective control siRNA, as assessed by Mann-Whitney $t$ test $(p \leq 0.05)$.

several representative proteins whose genes had been strongly upregulated or downregulated in vitro. We injected TGF $\beta+$ LPS +IFN $\gamma$ or PBS as a control into the frontal, sensorimotor cortex of wild-type mice. After survival times of 1-5 d, double staining immunohistochemistry was conducted for the canonical marker of reactive astrocytes, glial fibrillary acidic protein (GFAP; Sofroniew, 2009), in combination with various other proteins. In particular, we examined CXCL1, CXCL10, and CCL7 as three representative proteins whose genes had been highly upregulated by exposure to TGF $\beta+\mathrm{LPS}+\mathrm{IFN} \gamma$ in vitro (Table 1 ) and IL- 6 as a representative protein whose gene was synergisti- cally upregulated by combinatorial interactions of TGF $\beta+$ LPS + IFN $\gamma$ (Fig. 2, Table 2). We also examined ADRA2A as a representative protein whose gene had been strongly downregulated in vitro (Fig. 5, Table 8 ) and that we had studied functionally (Figs. 7, 8).

In agreement with previous reports (Myer et al., 2006), we found that in the central layers of naive cerebral cortex that was not injected, GFAP expression was low and could be detected by immunohistochemistry only in randomly scattered cells (Fig. $10 \mathrm{~A}$ ). As expected, GFAP expression was upregulated in the immediate vicinity of the injection sites after injection of either PBS 

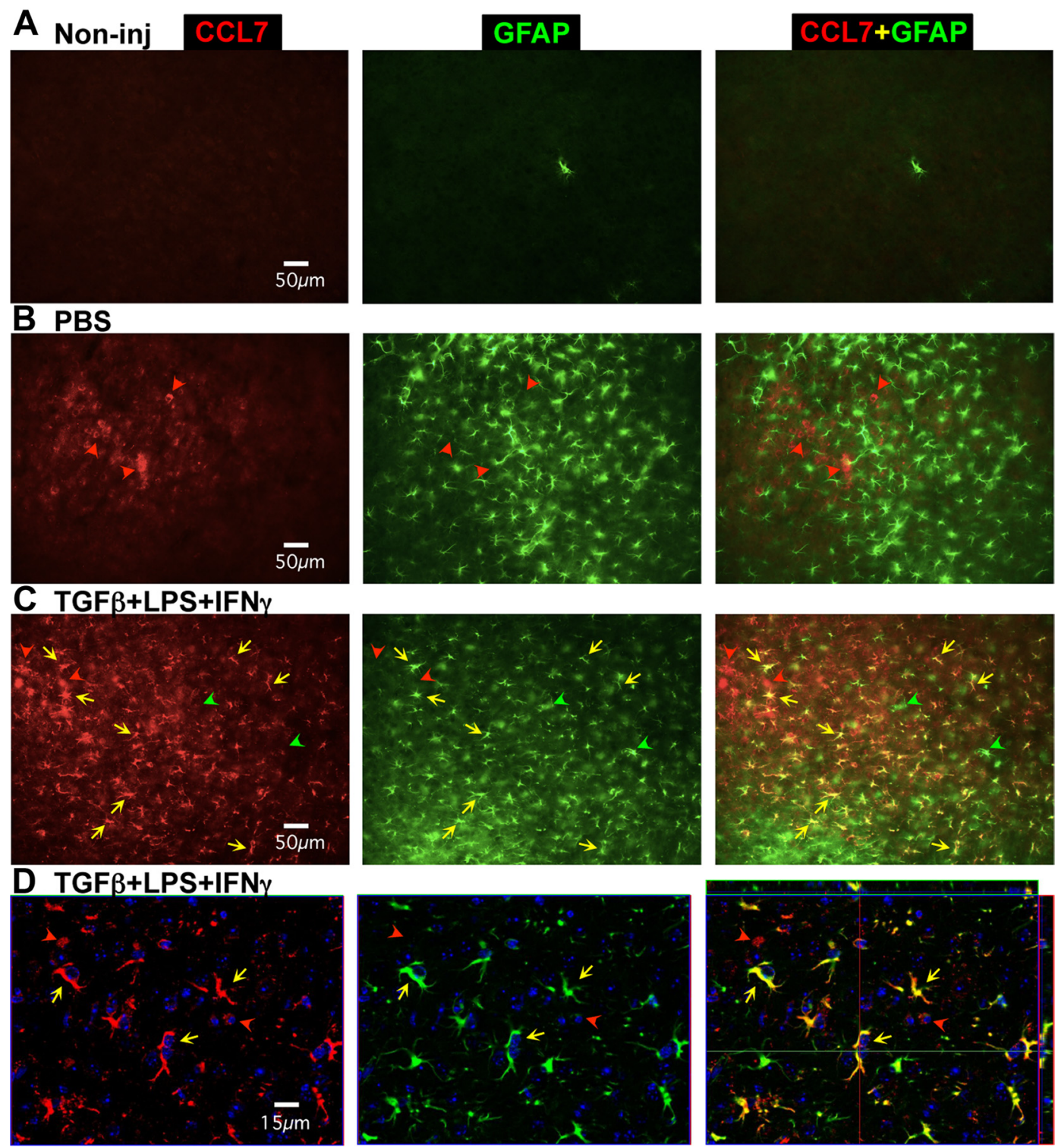

Figure 10. Changes in expression of GFAP and CCL7 induced in vivo by injection of PBS or TGF $\beta+$ LPS +IFN $\gamma$ into cerebral cortex. $A-D$, Single channel and merged two-color fluorescence survey $(\boldsymbol{A}-\boldsymbol{C})$ and detail (D) images of immunohistochemical staining for CCL7 (red) and GFAP (green) in mid-layers (3-5) of cerebral cortex of wild-type mice that were either noninjected ( $\boldsymbol{A})$ or injected with PBS (B) or TGF $\beta+$ LPS + IFN $\gamma 5$ d previously (C, D). D, Nuclei are counterstained with DAPI (blue) and the images were obtained using confocal microscopy. $\boldsymbol{A}$, In noninjected cortex, CCL7 is not detectably expressed by any cells and GFAP is detectable in only one astrocyte in this frame. $\boldsymbol{B}$, In PBS-injected cortex, CCL7 is expressed by a few cells that do not express GFAP (red arrowheads), whereas GFAP is detectable in many reactive astrocytes in the immediate vicinity of the injection site. $C, D, \ln T G F \beta+L P S+I F N \gamma$-injected cortex, $C$, $\beta$ is expressed both by cells that do not express GFAP (red arrowheads) as well as by many GFAP-expressing reactive astrocytes (yellow arrows). Some GFAP-expressing reactive astrocytes express little or no detectable CCL7 (green arrowheads).

(Fig. $10 B$ ) or TGF $\beta+$ LPS + IFN $\gamma$ (Fig. 10C). Interestingly, the level of GFAP increase in individual astrocytes did not differ substantively in cortex injected with either PBS or TGF $\beta+$ LPS + IFN $\gamma$ (Fig. $10 B, C$ ), but the cortical area over which the increased GFAP expression occurred was larger in mice injected with TGF $\beta+$ LPS + IFN $\gamma$.

In noninjected cortex, we found that none of the four molecules examined for potential upregulation, CXCL1, CXCL10, CCL7, and IL-6, could be detected in any cell type (Fig. 10 A, representative example of CCL7). In cortex injected with PBS, three of these molecules, CXCL1, CXCL10, and CCL7, could not be detected in any reactive astrocytes even though these astrocytes had upregulated GFAP (Figs. $10 B, 11 A-C$ ), whereas a few GFAP-expressing reactive astrocytes could be found that expressed small amounts of detectable IL-6 (Fig. 11D). In addition, after PBS injection these molecules were detectable in cells that were clearly not astrocytes as defined by size, shape, and lack of GFAP expression (Figs. $10 B, 11 A-D$ ).

In cortex injected with TGF $\beta+\mathrm{LPS}+\mathrm{IFN} \gamma$, all four molecules examined for potential upregulation, CXCL1, CXCL10, CCL7, and IL-6, were immunohistochemically detectable in many cells that expressed GFAP and were clearly reactive astrocytes as defined by size and shape (Figs. 10C,D, $11 A-E$ ). Interestingly, the expression levels of all four molecules appeared to be markedly heterogeneous in reactive astrocytes, such that some astrocytes expressed high levels, some low, and some undetectable levels of the molecules (Figs. 10C,D, $11 \mathrm{~A}-$ $E)$. In addition, the expression patterns and timing differed among the four molecules, such that expression by astrocytes of CXCL1 and CXCL10 peaked at the early time points and had disappeared by $5 \mathrm{~d}$, whereas expression of CCL7 and IL- 6 persisted in many astrocytes through $5 \mathrm{~d}$ (Fig. 10). 
These findings confirm in vivo the upregulation by TGF $\beta+$ LPS +IFN $\gamma$ of several representative molecules whose genes we identified as highly upregulated in vitro. In addition, these in vivo findings support our in vitro observation that treatment of primary cultures of cortical astrocytes with TGF $\beta+$ LPS + IFN $\gamma$ did not further upregulate expression of GFAP (Table 6). Primary cortical astrocyte cultures express high levels of GFAP and have long been thought by some investigators to exhibit certain characteristics of reactive astrocytes, such as elevated levels of GFAP expression. Elegant studies combining large-scale genetic analyses of different types of in vitro and in vivo preparations of astrocytes have now clearly shown that primary cortical astrocyte cultures are more similar to reactive astrocytes than to astrocytes in healthy tissue (Foo et al., 2011; Zamanian et al., 2012). Our observation that GFAP is essentially undetectable in astrocytes in unmanipulated cortical tissue in vivo and is upregulated to the same degree in individual cortical astrocytes after injection in vivo of either PBS or TGF $\beta+\mathrm{LPS}+\mathrm{IFN} \gamma$ is consistent with the notion that primary cultures of cortical astrocytes are in a reactive state in which GFAP is already upregulated and was not further upregulated by our doses of TGF $\beta+$ LPS + IFN $\gamma$.

For the molecule being examined for potential downregulation, ADRA2A, we found that in cerebral cortex injected with PBS, ADRA2A could be detected by immunohistochemistry in GFAPpositive astrocytes in cerebral cortex in the immediate vicinity of the PBS injections and that expression levels were heterogeneous among different astrocytes, with some exhibiting high expression levels (Fig. $11 E$ ) and others low or undetectable expression levels. In cerebral cortex injected with TGF $\beta+$ LPS + IFN $\gamma$, despite the large number of GFAP-positive reactive astrocytes, there was an essential absence of ADRA2A-positive astrocytes (Fig. 11E). These findings confirm in vivo the downregulation by TGF $\beta+$ LPS +IFN $\gamma$ of a representative molecule whose gene we identified as markedly downregulated in vitro and are consistent with our functional observations that treatment with TGF $\beta+$ LPS + IFN $\gamma$ markedly reduced both the peak response and the percentage responders of astrocytes stimulated in vitro with the ADRA2A-selective agonist guanfacine (Fig. 7).

\section{Discussion}

In this study we found that stimulation of astrocytes with the inflammatory mediators TGF- $\beta 1$, LPS, and IFN $\gamma$ alone and in combination significantly altered the expression of many genes, molecular networks, and functional pathways. Combinatorial stimulation with all three mediators led to both additive and synergistic changes, and substantially modulated numerous astrocyte molecular networks and pathways associated with immune- and injury-related functions. Expression levels of many GPCRs and G-protein effectors involved in calcium signaling were significantly altered, and these expression changes were accompanied by parallel changes in astrocyte calcium signaling evoked by corresponding GPCR-specific ligands. Astrocytes play many essential roles in healthy CNS (Barres, 2008; Attwell et al., 2010; Halassa and Haydon, 2010) and respond to CNS insults through a process known as reactive astrogliosis, in which astrocytes modify their gene expression in response to stimulation by numerous factors (Pekny and Nilsson, 2005; Sofroniew, 2009; Hamby and Sofroniew, 2010). The impact of inflammatory mediators on the functions of astrocytes and reactive astrocytes is poorly understood and is of increasing interest with the growing awareness of critical roles of astrocytes in healthy and injured CNS (Barres, 2008; Nedergaard et al., 2010; Sofroniew and Vinters, 2010). The findings of this study shed light on how inflam- matory stimuli, alone and in combination, may influence a wide variety of astrocyte functions.

\section{Additive and synergistic effects of TGF- $\beta 1$, LPS, and IFN $\gamma$ on astrocyte genomic profiles}

There is an extensive and well reviewed literature on the effects of many different individual inflammatory mediators on the expression by astrocytes of numerous individual genes (Eddleston and Mucke, 1993; John et al., 2003; Sofroniew, 2009). Microarray profiling has previously been applied to generate transcriptomic datasets of astrocytes acutely isolated from either healthy CNS (Lovatt et al., 2007; Cahoy et al., 2008) or CNS after stroke or peripheral LPS injections (Zamanian et al., 2012) or hyperammonemia (LichterKonecki et al., 2008), or astrocyte cell cultures prepared by a novel immunopanning procedure (Foo et al., 2011), or primary astrocyte cell cultures treated with LPS or IL-1 (Pang et al., 2001; John et al., 2005). Our findings here extend these studies not only by documenting transcriptome changes induced in primary astrocyte cultures by the regulatory cytokine, TGF- $\beta 1$, and the canonical innate inflammatory mediators, LPS + IFN $\gamma$, but also by demonstrating that combinatorial interactions among these inflammatory mediators can lead to synergistic changes. Notably, using highly stringent criteria, we found that combinatorial treatment with TGF $\beta+$ LPS + IFN $\gamma$ resulted in synergistic changes in $>380$ gene probes that could not be predicted by summing the effects of individual treatments with TGF- $\beta 1$ or LPS+IFN $\gamma$ alone. qRT-PCR confirmed synergistic regulation of selected genes. These findings show that synergistic interactions of inflammatory mediators can regulate astrocyte production of molecules with key functions in the CNS response to inflammation (IL-6, SEMA4a, NOS-2, etc.) in ways not predicted by individual effects of those mediators. The importance of combinatorial interactions among different inflammatory stimuli in regulating specific responses of T-cells is well documented (Korn et al., 2009). Our findings show that combinatorial exposure to multiple inflammatory mediators can lead to large-scale synergistic and unpredictable changes in astrocyte gene expression. Further study is warranted to understand the biological implications and intracellular signaling mechanisms.

\section{In vivo confirmation of in vitro observations}

We confirmed by immunohistochemistry that several representative proteins whose genes we identified as highly upregulated or downregulated in vitro were upregulated or downregulated in astrocytes in vivo after injection of TGF $\beta+$ LPS + IFN $\gamma$ into cerebral cortex. Our findings in vivo and in vitro are in broad agreement with a recent analysis of genome-wide changes induced in astrocytes in vivo by peripheral treatment with LPS, which showed pronounced upregulation by reactive astrocytes (compared with nonreactive astrocytes) of many genes encoding the same chemokines, cytokines, and other molecules found in our study in vitro (Zamanian et al., 2012). Interestingly, our immunohistochemical analysis at the single cell in vivo revealed that the patterns, levels, and time course of expression of GFAP, chemokine, cytokines, and other molecules was markedly heterogeneous among different individual reactive astrocytes after two different triggers of reactivity, injection of PBS, or TGF $\beta+$ LPS + IFN $\gamma$. These observations provide further support for the notion that reactive astrogliosis is not a stereotypic all-or-none response as once believed, but rather is a highly varied and heterogeneous process that can involve many different changes in gene expression that can vary over time and can resolve, as regulated by many different specific signaling mechanisms in a context and tem- 
A
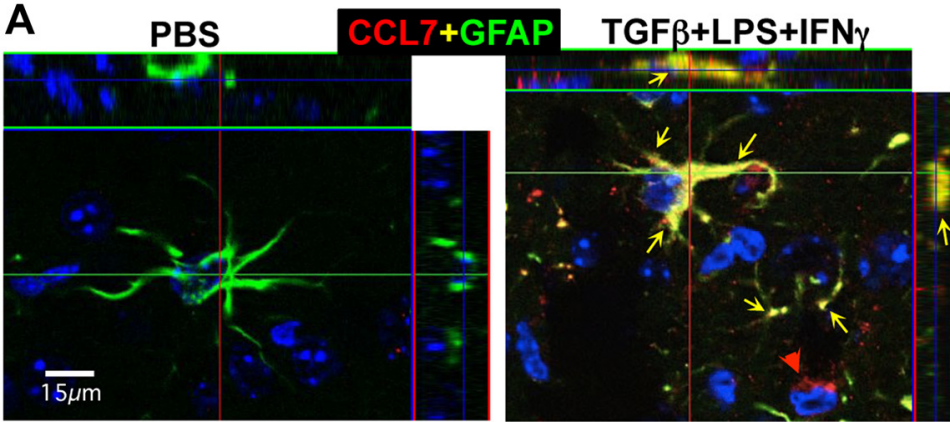

B

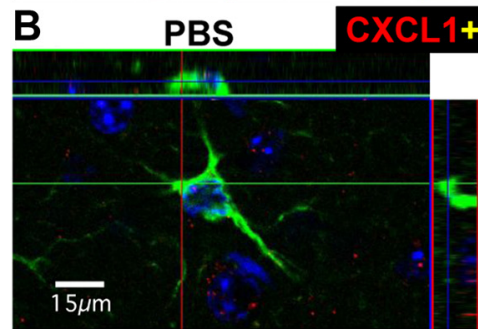

+GFAP TGF $\beta+$ LPS+IFN $\gamma$

C
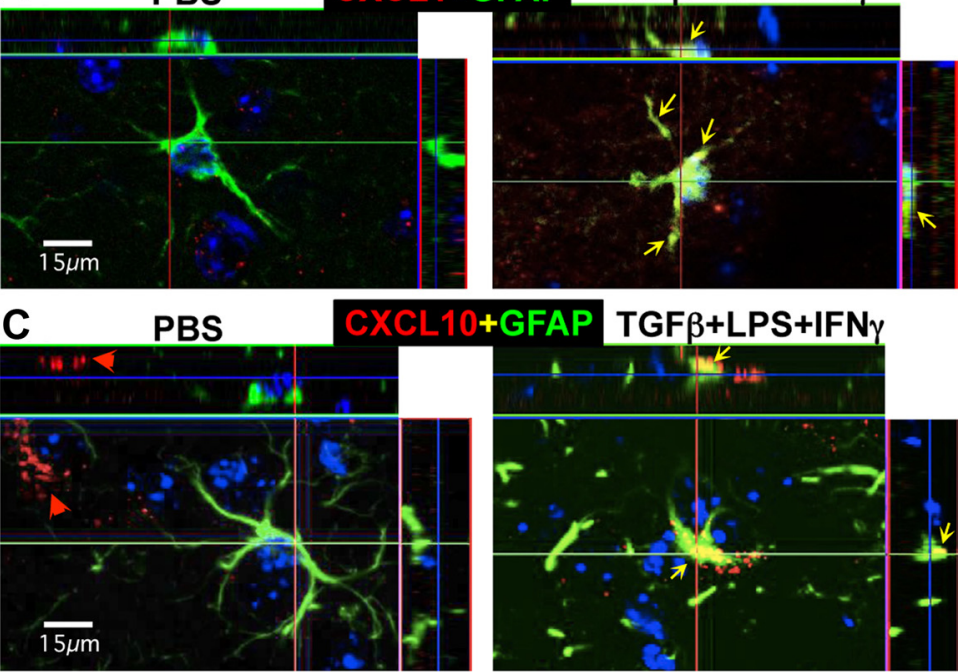

D
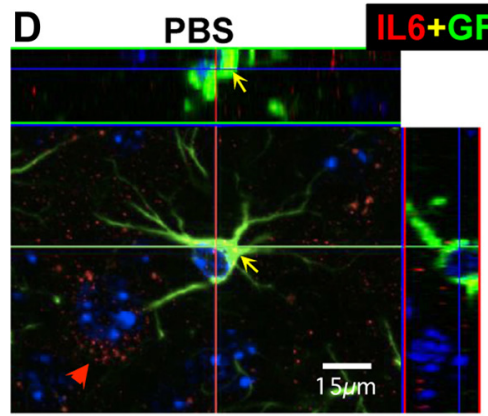

L6+GFAP

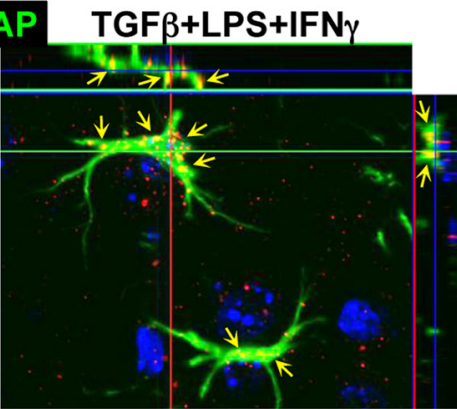

$\mathbf{E}$

ADRA2A+GFAP TGF $\beta+$ LPS+IFN $\gamma$
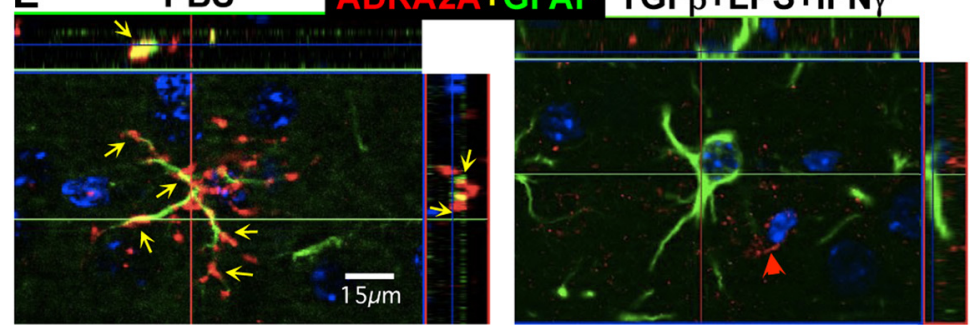

Figure 11. Changes in expression of $C \mathrm{CL} 7, \mathrm{CXCL} 1, \mathrm{CXCL} 10, \mathrm{IL}-6$, and $A D R A 2 A$ induced in vivo in GFAP-expressing reactive astrocytes by injection of TGF $\beta+$ LPS + IFN $\gamma$ into cerebral cortex. $\boldsymbol{A}-\boldsymbol{E}$, Multicolor, fluorescence, and confocal microscopic images of immunohistochemical staining for CCL7, CXCL1, CXCL10, IL-6, or ADRA2A (red), in combination with GFAP (green) and the nuclear stain, DAPI (blue), in mid-layers (3-5) of cerebral cortex of wild-type mice injected with PBS or $\mathrm{TGF} \beta+\mathrm{LPS}+$ IFN $\gamma 1$ d previously. Red arrowheads denote cells that express only CCL7, CXCL1, CXCL10, IL-6, or ADRA2A and do not express GFAP. Yellow arrows denote sties of coexpression of CCL7, CXCL1, CXCL10, IL-6, or ADRA2A within reactive astrocytes that also express GFAP. Note that after injection of PBS, GFAP-expressing reactive astrocytes do not express detectable levels of $C C L 7(\boldsymbol{A}), \mathrm{CXCL}_{1}(\boldsymbol{B})$, and $\mathrm{CXCL10}(\boldsymbol{C})$, whereas some reactive astrocytes do express small amounts of IL-6 $(\boldsymbol{D})$ and some robustly express ADRA2A $(\boldsymbol{E})$. After injection of TGF $\beta+$ LPS + IFN $\gamma$, many reactive astrocytes express detectable levels of $C C L 7(\boldsymbol{A}), \operatorname{CXCL1}(\boldsymbol{B})$, and $\mathrm{CXCL10}(\boldsymbol{C})$, and upregulate expression of IL-6 (D) and markedly downregulate expression of $\operatorname{ADRA} 2 \mathrm{~A}(\boldsymbol{E})$. porally dependent manner (Sofroniew, 2009). In addition, our present in vitro and in vivo findings extend these ideas by providing direct evidence that exposure to inflammatory mediators can alter the nature of astrocyte reactivity and shift it toward exerting more proinflammatory effects. In this context it is interesting to speculate that peripheral infections that produce such inflammatory mediators may exert pronounced and context-altering effects on astrocyte reactivity, thereby having important and as yet poorly understood repercussions in a wide variety of CNS disorders in which astrocyte reactivity is prominent (Sofroniew and Vinters, 2010).

\section{TGF $\beta+$ LPS + IFN $\gamma$ modulates}

astrocyte genomic networks toward immune- and injury-related functions A striking feature of the effects of combinatorial treatment with TGF $\beta+\mathrm{LPS}+\mathrm{IFN} \gamma$ on astrocytes is that all of the top 5 most upregulated genes were chemokines, and 7 of the top 10 were related to immune or inflammatory functions, all of which exhibited pronounced increases in the range of $\sim 125$ - to 250 -fold (7-8 $\log _{2}$-fold). In addition, bioinformatic analysis revealed that the top regulated Associated Network Function was antigen presentation, and that 17 of the top 20 Canonical Pathways involved chemokine or cytokine signaling or innate immune regulation. Highly upregulated individual genes included numerous chemokines, cytokines, growth factors, their receptors, and components of their signaling pathways. Together, these findings add to the growing body of evidence that astrocytes play complex roles in CNS immune and inflammatory responses that may involve both pro- and anti-inflammatory effects (Bush et al., 1999; Brambilla et al., 2005; Okada et al., 2006; Herrmann et al., 2008; Sofroniew, 2009; Voskuhl et al., 2009; Li et al., 2011). Here, we both confirm, and newly identify, a large number of specific candidate molecules whose production by astrocytes is regulated by inflammatory stimuli that could potentially participate in or mediate such effects. For example, CXCL12, CCL2, and CD40 have all been shown to regulate $\mathrm{T}$-cell trafficking in the CNS (Mahad and Ransohoff, 2003; Sitati et al., 2007; McCandless et al., 2008; Moll et al., 2009; Patel et al., 2010). IL-11 attenuates inflammation and protects myelin in experimental autoimmune encephalomyelitis (EAE) (Gurfein et al., 2009). IL-15 is implicated in T-, B-, and natural killer (NK) cell activation and proliferation (Steel et al., 2012). CCL8 is implicated in eosinophil recruitment (Islam et al., 2011). IL-6 is impli- 
cated as an essential inducer of pathogenic antibody production in neuromyelitis optica (NMO) (Chihara et al., 2011). Combinational interactions between IL- 6 and TGF- $\beta 1$ underlie the conversion of CD4 T-cells into Th17 T-cells that are widely implicated in CNS immune defense and autoimmune disorders including EAE, NMO, and multiple sclerosis (MS) (Korn et al., 2009). We show here that TGF $\beta+$ LPS + IFN $\gamma$ markedly upregulated astrocyte production of all of these molecules. Our findings strongly support the notion that astrocytes are key regulators of CNS immune and inflammatory responses, and identify numerous novel candidate molecules that may mediate astrocyte effects on CNS immune and inflammatory responses. We provide transcriptomic datasets with which to generate hypotheses regarding astrocyte molecules regulated by these inflammatory mediators that may be involved in astrocyte roles in autoimmune diseases like MS, NMO, and EAE, as well as more generally in CNS inflammation associated with diverse disorders including stroke, trauma, neurodegeneration, and infection.

Bioinformatic analysis also revealed that combinatorial stimulation with TGF $\beta+$ LPS + IFN $\gamma$ substantially modulated molecular and cellular networks associated with cell death, cell compromise, and cell injury, as well as regulation of cell morphology, cell maintenance, cell compromise, and cell growth and proliferation. These observations are consistent with the large body of evidence that reactive astrocytes undergo cell hypertrophy and proliferation as well as cell injury and death while subserving critical roles in the response to CNS injury and tissue repair. This notion was supported further by analysis of individual genes (Table 6), which indicated pronounced regulation of a wide variety of molecules associated with such responses, including numerous growth factors, molecules involved in extracellular matrix remodeling, and enzymes that generate small molecule mediators involved in regulation of blood flow. Notably, many of the changes induced by inflammatory stimuli in astrocytes may be adaptive and beneficial in some contexts, such as response to infectious agents, but might be harmful in other contexts where overexpression of certain chemokines and cytokines may contribute to autoimmune disease, or the overproduction of certain molecules such as nitric oxide might contribute to neural dysfunction or degeneration (Sofroniew, 2009; Sofroniew and Vinters, 2010).

\section{TGF $\beta+$ LPS + IFN $\gamma$ modulate astrocyte calcium signaling}

Calcium signaling is broadly implicated in regulating many aspects of cell function (Clapham, 2007) and can be modulated by tissue injury in ways that alter cell functions (Sayeed, 2000). Astrocyte calcium signaling is under investigation for a potential role in mediating astrocyte influences on neuronal activity and blood flow in the healthy CNS (Iadecola and Nedergaard, 2007; Gordon et al., 2008; Attwell et al., 2010; Halassa and Haydon, 2010), as well as in responses to ischemia, cell injury, edema/ osmotic stress, or inflammation (Duffy and MacVicar, 1996; Neary et al., 2003; Delbro et al., 2009; Thrane et al., 2011). The impact of inflammatory mediators on astrocyte calcium signaling is poorly understood. Our genomic screening analysis revealed that exposure of astrocytes to the combinatorial inflammatory stimuli of TGF- $\beta 1$, LPS, and IFN $\gamma$, led to substantial changes in the expression of many genes among GPCRs and their intracellular effector molecules involved in inositol trisphosphatemediated calcium signaling. Notably, there was a significant downward trend in the GPCR-encoding genes that were regulated, although not all genes were downregulated. At the functional level, we found that the changes in gene expression were accompanied by parallel changes in ligand-evoked calcium sig- naling. These findings are consistent with and extend previous reports regarding the extensive repertoire of GPCRs expressed by astrocytes (Duffy and MacVicar, 1995; Verkhratsky et al., 1998; Calì and Bezzi, 2010). Importantly, our findings demonstrate that inflammatory stimuli can significantly alter astrocyte calcium signaling elicited by multiple GPCRs. Although the downstream functional implications of these changes in astrocyte calcium signaling are not yet clear, alterations in GPCR-evoked astrocyte $\left[\mathrm{Ca}^{2+}\right]_{i}$ transients may represent mechanisms whereby CNS inflammation influences various functions in reactive astrocytes. Recent findings suggest that reactive astrogliosis in response to viral infection can significantly alter neuronal function (Ortinski et al., 2010). Our findings extend these observations by demonstrating that inflammatory stimuli significantly modulate astrocyte calcium signaling in multiple ways. The large number of different GPCRs that trigger distinct forms of astrocyte $\left[\mathrm{Ca}^{2+}\right]_{i}$ transients that are modulated by inflammatory stimuli points toward the potential for selective pharmacological manipulation and novel therapeutic strategies that may be relevant in diverse CNS disorders.

\section{References}

Abbracchio MP, Boeynaems JM, Barnard EA, Boyer JL, Kennedy C, MirasPortugal MT, King BF, Gachet C, Jacobson KA, Weisman GA, Burnstock G (2003) Characterization of the UDP-glucose receptor (re-named here the $\mathrm{P} 2 \mathrm{Y} 14$ receptor) adds diversity to the $\mathrm{P} 2 \mathrm{Y}$ receptor family. Trends Pharmacol Sci 24:52-55.

Ata AK, Funa K, Olsson Y (1997) Expression of various TGF-beta isoforms and type I receptor in necrotizing human brain lesions. Acta Neuropathol 93:326-333.

Attwell D, Buchan AM, Charpak S, Lauritzen M, Macvicar BA, Newman EA (2010) Glial and neuronal control of brain blood flow. Nature 468:232243.

Barres BA (2008) The mystery and magic of glia: a perspective on their roles in health and disease. Neuron 60:430-440.

Brambilla R, Bracchi-Ricard V, Hu WH, Frydel B, Bramwell A, Karmally S, Green EJ, Bethea JR (2005) Inhibition of astroglial nuclear factor kappaB reduces inflammation and improves functional recovery after spinal cord injury. J Exp Med 202:145-156.

Bush TG, Puvanachandra N, Horner CH, Polito A, Ostenfeld T, Svendsen CN, Mucke L, Johnson MH, Sofroniew MV (1999) Leukocyte infiltration, neuronal degeneration and neurite outgrowth after ablation of scarforming, reactive astrocytes in adult transgenic mice. Neuron 23:297-308.

Cahoy JD, Emery B, Kaushal A, Foo LC, Zamanian JL, Christopherson KS, Xing Y, Lubischer JL, Krieg PA, Krupenko SA, Thompson WJ, Barres BA (2008) A transcriptome database for astrocytes, neurons, and oligodendrocytes: a new resource for understanding brain development and function. J Neurosci 28:264-278.

Calì C, Bezzi P (2010) CXCR4-mediated glutamate exocytosis from astrocytes. J Neuroimmunol 224:13-21.

Chihara N, Aranami T, Sato W, Miyazaki Y, Miyake S, Okamoto T, Ogawa M, Toda T, Yamamura T (2011) Interleukin 6 signaling promotes antiaquaporin 4 autoantibody production from plasmablasts in neuromyelitis optica. Proc Natl Acad Sci U S A 108:3701-3706.

Clapham DE (2007) Calcium signaling. Cell 131:1047-1058.

Coppola G (2011) Designing, performing, and interpreting a microarraybased gene expression study. Methods Mol Biol 793:417-439.

Coppola G, Marmolino D, Lu D, Wang Q, Cnop M, Rai M, Acquaviva F, Cocozza S, Pandolfo M, Geschwind DH (2009) Functional genomic analysis of frataxin deficiency reveals tissue-specific alterations and identifies the PPARgamma pathway as a therapeutic target in Friedreich's ataxia. Hum Mol Genet 18:2452-2461.

Daginakatte GC, Gadzinski A, Emnett RJ, Stark JL, Gonzales ER, Yan P, Lee JM, Cross AH, Gutmann DH (2008) Expression profiling identifies a molecular signature of reactive astrocytes stimulated by cyclic AMP or proinflammatory cytokines. Exp Neurol 210:261-267.

Delbro D, Westerlund A, Björklund U, Hansson E (2009) In inflammatory reactive astrocytes co-cultured with brain endothelial cells nicotineevoked $\mathrm{Ca}(2+)$ transients are attenuated due to interleukin-1beta release and rearrangement of actin filaments. Neuroscience 159:770-779. 
Duffy S, MacVicar BA (1995) Adrenergic calcium signaling in astrocyte networks within the hippocampal slice. J Neurosci 15:5535-5550.

Duffy S, MacVicar BA (1996) In vitro ischemia promotes calcium influx and intracellular calcium release in hippocampal astrocytes. J Neurosci 16:71-81.

Eddleston M, Mucke L (1993) Molecular profile of reactive astrocytes-implications for their role in neurological disease. Neuroscience 54:15-36.

Edgar R, Domrachev M, Lash AE (2002) Gene Expression Omnibus: NCBI gene expression and hybridization array data repository. Nucleic Acids Res 30:207-210.

Faulkner JR, Herrmann JE, Woo MJ, Tansey KE, Doan NB, Sofroniew MV (2004) Reactive astrocytes protect tissue and preserve function after spinal cord injury. J Neurosci 24:2143-2155.

Foo LC, Allen NJ, Bushong EA, Ventura PB, Chung WS, Zhou L, Cahoy JD, Daneman R, Zong H, Ellisman MH, Barres BA (2011) Development of a method for the purification and culture of rodent astrocytes. Neuron 71:799-811.

Friedman A, Dingledine R (2011) Molecular cascades that mediate the influence of inflammation on epilepsy. Epilepsia 52 [Suppl 3]:33-39.

Gordon GR, Choi HB, Rungta RL, Ellis-Davies GC, MacVicar BA (2008) Brain metabolism dictates the polarity of astrocyte control over arterioles. Nature 456:745-749.

Gurfein BT, Zhang Y, López CB, Argaw AT, Zameer A, Moran TM, John GR (2009) IL-11 regulates autoimmune demyelination. J Immunol 183: $4229-4240$.

Halassa MM, Haydon PG (2010) Integrated brain circuits: astrocytic networks modulate neuronal activity and behavior. Annu Rev Physiol 72: 335-355.

Hamby ME, Sofroniew MV (2010) Reactive astrocytes as therapeutic targets for CNS disorders. Neurotherapeutics 7:494-506.

Hamby ME, Hewett JA, Hewett SJ (2006a) TGF-betal potentiates astrocytic nitric oxide production by expanding the population of astrocytes that express NOS-2. Glia 54:566-577.

Hamby ME, Uliasz TF, Hewett SJ, Hewett JA (2006b) Characterization of an improved procedure for the removal of microglia from confluent monolayers of primary astrocytes. J Neurosci Methods 150:128-137.

Hamby ME, Hewett JA, Hewett SJ (2008) TGF-betal reduces the heterogeneity of astrocytic cyclooxygenase- 2 and nitric oxide synthase- 2 gene expression in a stimulus-independent manner. Prostaglandins Other Lipid Mediat 85:115-124.

Hamby ME, Hewett JA, Hewett SJ (2010) Smad3-dependent signaling underlies the TGF-beta1-mediated enhancement in astrocytic iNOS expression. Glia 58:1282-1891.

Herrmann JE, Imura T, Song B, Qi J, Ao Y, Nguyen TK, Korsak RA, Takeda K, Akira S, Sofroniew MV (2008) STAT3 is a critical regulator of astrogliosis and scar formation after spinal cord injury. J Neurosci 28:7231-7243.

Holm TH, Draeby D, Owens T (2012) Microglia are required for astroglial toll-like receptor 4 response and for optimal TLR2 and TLR3 response. Glia 60:630-638.

Iadecola C, Nedergaard M (2007) Glial regulation of the cerebral microvasculature. Nat Neurosci 10:1369-1376.

Islam SA, Chang DS, Colvin RA, Byrne MH, McCully ML, Moser B, Lira SA, Charo IF, Luster AD (2011) Mouse CCL8, a CCR8 agonist, promotes atopic dermatitis by recruiting IL-5 + T(H)2 cells. Nat Immunol 12:167177.

John GR, Lee SC, Brosnan CF (2003) Cytokines: Powerful regulators of glial cell activation. Neuroscientist 9:10-22.

John GR, Lee SC, Song X, Rivieccio M, Brosnan CF (2005) IL-1-regulated responses in astrocytes: relevance to injury and recovery. Glia 49:161-176.

Korn T, Bettelli E, Oukka M, Kuchroo VK (2009) IL-17 and Th17 Cells. Annu Rev Immunol 27:485-517.

Krupinski J, Kumar P, Kumar S, Kaluza J (1996) Increased expression of TGF-beta 1 in brain tissue after ischemic stroke in humans. Stroke 27: 852-857.

Lattin J, Zidar DA, Schroder K, Kellie S, Hume DA, Sweet MJ (2007) G-protein-coupled receptor expression, function, and signaling in macrophages. J Leukoc Biol 82:16-32.

Li L, Zhang H, Varrin-Doyer M, Zamvil SS, Verkman AS (2011) Proinflammatory role of aquaporin- 4 in autoimmune neuroinflammation. FASEB J 25:1556-1566.

Lichter-Konecki U, Mangin JM, Gordish-Dressman H, Hoffman EP, Gallo V (2008) Gene expression profiling of astrocytes from hyperammonemic mice reveals altered pathways for water and potassium homeostasis in vivo. Glia 56:365-377.

Lindholm D, Castrén E, Kiefer R, Zafra F, Thoenen H (1992) Transforming growth factor-beta 1 in the rat brain: increase after injury and inhibition of astrocyte proliferation. J Cell Biol 117:395-400.

Lovatt D, Sonnewald U, Waagepetersen HS, Schousboe A, He W, Lin JH, Han X, Takano T, Wang S, Sim FJ, Goldman SA, Nedergaard M (2007) The transcriptome and metabolic gene signature of protoplasmic astrocytes in the adult murine cortex. J Neurosci 27:12255-12266.

Lucas SM, Rothwell NJ, Gibson RM (2006) The role of inflammation in CNS injury and disease. Br J Pharmacol 147 [Suppl 1]:S232-S240.

Mahad DJ, Ransohoff RM (2003) The role of MCP-1 (CCL2) and CCR2 in multiple sclerosis and experimental autoimmune encephalomyelitis (EAE). Semin Immunol 15:23-32.

McCandless EE, Zhang B, Diamond MS, Klein RS (2008) CXCR4 antagonism increases $\mathrm{T}$ cell trafficking in the central nervous system and improves survival from West Nile virus encephalitis. Proc Natl Acad Sci U S A 105:11270-11275.

Moll NM, Cossoy MB, Fisher E, Staugaitis SM, Tucky BH, Rietsch AM, Chang A, Fox RJ, Trapp BD, Ransohoff RM (2009) Imaging correlates of leukocyte accumulation and CXCR4/CXCL12 in multiple sclerosis. Arch Neurol 66:44-53.

Myer DJ, Gurkoff GG, Lee SM, Hovda DA, Sofroniew MV (2006) Essential protective roles of reactive astrocytes in traumatic brain injury. Brain 129:2761-2772.

Neary JT, Kang Y, Willoughby KA, Ellis EF (2003) Activation of extracellular signal-regulated kinase by stretch-induced injury in astrocytes involves extracellular ATP and P2 purinergic receptors. J Neurosci 23: $2348-2356$.

Nedergaard M, Rodríguez JJ, Verkhratsky A (2010) Glial calcium and diseases of the nervous system. Cell Calcium 47:140-149.

Okada S, Nakamura M, Katoh H, Miyao T, Shimazaki T, Ishii K, Yamane J, Yoshimura A, Iwamoto Y, Toyama Y, Okano H (2006) Conditional ablation of Stat 3 or Socs3 discloses a dual role for reactive astrocytes after spinal cord injury. Nat Med 12:829-834.

Ortinski PI, Dong J, Mungenast A, Yue C, Takano H, Watson DJ, Haydon PG, Coulter DA (2010) Selective induction of astrocytic gliosis generates deficits in neuronal inhibition. Nat Neurosci 13:584-591.

Pang Y, Cai Z, Rhodes PG (2001) Analysis of genes differentially expressed in astrocytes stimulated with lipopolysaccharide using cDNA arrays. Brain Res 914:15-22.

Patel JR, McCandless EE, Dorsey D, Klein RS (2010) CXCR4 promotes differentiation of oligodendrocyte progenitors and remyelination. Proc Natl Acad Sci U S A 107:11062-11067.

Pekny M, Nilsson M (2005) Astrocyte activation and reactive gliosis. Glia 50:427-434.

Raetz CR, Whitfield C (2002) Lipopolysaccharide endotoxins. Annu Rev Biochem 71:635-700.

Sarafian TA, Montes C, Imura T, Qi J, Coppola G, Geschwind DH, Sofroniew MV (2010) Disruption of astrocyte STAT3 signaling decreases mitochondrial function and increases oxidative stress in vitro. PLoS One 5:e9532.

Sayeed MM (2000) Signaling mechanisms of altered cellular responses in trauma, burn, and sepsis: role of Ca2 +. Arch Surg 135:1432-1442.

Schroder K, Hertzog PJ, Ravasi T, Hume DA (2004) Interferon-gamma: an overview of signals, mechanisms and functions. J Leukoc Biol 75:163-189.

Sharman JL, Mpamhanga CP, Spedding M, Germain P, Staels B, Dacquet C, Laudet V, Harmar AJ (2011) IUPHAR-DB: new receptors and tools for easy searching and visualization of pharmacological data. Nucleic Acids Res 39:D534-D538.

Shigetomi E, Khakh BS (2009) Measuring near plasma membrane and global intracellular calcium dynamics in astrocytes. J Vis Exp 26:pii:1142.

Shigetomi E, Tong X, Kwan KY, Corey DP, Khakh BS (2012) TRPA1 channels regulate astrocyte resting calcium and inhibitory synapse efficacy through GAT-3. Nat Neurosci 15:70-80.

Sitati E, McCandless EE, Klein RS, Diamond MS (2007) CD40-CD40 ligand interactions promote trafficking of CD8 $+\mathrm{T}$ cells into the brain and protection against West Nile virus encephalitis. J Virol 81:9801-9811.

Smyth GK (2004) Linear models and empirical Bayes methods for assessing differential expression in microarray experiments. In: Statistical applications in genetics and molecular biology. Berkeley, CA: Berkeley Electronic Press. E-book available at http://www.bepress.com/sagmb/vol3/iss1/art3. 
Sofroniew MV (2009) Molecular dissection of reactive astrogliosis and glial scar formation. Trends Neurosci 32:638-647.

Sofroniew MV, Vinters HV (2010) Astrocytes: biology and pathology. Acta Neuropathol 119:7-35.

Steel JC, Waldmann TA, Morris JC (2012) Interleukin-15 biology and its therapeutic implications in cancer. Trends Pharmacol Sci 33:35-41.

Swardfager W, Lanct^ot K, Rothenburg L, Wong A, Cappell J, Herrmann N (2010) A meta-analysis of cytokines in Alzheimer's disease. Biol Psychiatry 68:930-941.

Thrane AS, Rappold PM, Fujita T, Torres A, Bekar LK, Takano T, Peng W, Wang F, Thrane VR, Enger R, Haj-Yasein NN, Skare Ø, Holen T, Klung- land A, Ottersen OP, Nedergaard M, Nagelhus EA (2011) Critical role of aquaporin-4 (AQP4) in astrocytic Ca2 + signaling events elicited by cerebral edema. Proc Natl Acad Sci U S A 108:846-851.

Verkhratsky A, Orkand RK, Kettenmann H (1998) Glial calcium: homeostasis and signaling function. Physiol Rev 78:99-141.

Voskuhl RR, Peterson RS, Song B, Ao Y, Morales LB, Tiwari-Woodruff S, Sofroniew MV (2009) Reactive astrocytes form scar-like perivascular barriers to leukocytes during adaptive immune inflammation of the CNS. J Neurosci 29:11511-11522.

Zamanian JL, Xu L, Foo LC, Nouri N, Zhou L, Giffard RG, Barres BA (2012) Genomic analysis of reactive astrogliosis. J Neurosci 32:6391-6410. 